\title{
Transplacental immune modulation with a bacterial- derived agent protects against allergic airway inflammation
}

\author{
Kyle T. Mincham, ${ }^{1}$ Naomi M. Scott, ${ }^{1}$ Jean-Francois Lauzon-Joset, ${ }^{1}$ Jonatan Leffler, ${ }^{1}$ Alexander N. Larcombe, ${ }^{1,2}$ \\ Philip A. Stumbles, ${ }^{1,3,4}$ Sarah A. Robertson, ${ }^{5}$ Christian Pasquali, ${ }^{6}$ Patrick G. Holt, ${ }^{1}$ and Deborah H. Strickland ${ }^{1}$ \\ ${ }^{1}$ Telethon Kids Institute, University of Western Australia, Nedlands, Western Australia, Australia. ${ }^{2}$ Health, Safety and Environment, School of Public Health, Curtin University, Perth, Western Australia, \\ Australia. ${ }^{3}$ School of Veterinary and Life Sciences, Murdoch University, Perth, Western Australia, Australia. ${ }^{4}$ School of Paediatrics and Child Health, University of Western Australia, Subiaco, \\ Western Australia, Australia. ${ }^{5}$ Robinson Research Institute and School of Medicine, University of Adelaide, Adelaide, South Australia, Australia. ${ }^{6}$ OM Pharma SA, Geneva, Switzerland.
}

\begin{abstract}
Chronic allergic inflammatory diseases are a major cause of morbidity, with allergic asthma alone affecting over 300 million people worldwide. Epidemiological studies demonstrate that environmental stimuli are associated with either the promotion or prevention of disease. Major reductions in asthma prevalence are documented in European and US farming communities. Protection is associated with exposure of mothers during pregnancy to microbial breakdown products present in farm dusts and unprocessed foods and enhancement of innate immune competence in the children. We sought to develop a scientific rationale for progressing these findings toward clinical application for primary disease prevention. Treatment of pregnant mice with a defined, clinically approved immune modulator was shown to markedly reduce susceptibility of their offspring to development of the hallmark clinical features of allergic airway inflammatory disease. Mechanistically, offspring displayed enhanced dendritic cell-dependent airway mucosal immune surveillance function, which resulted in more efficient generation of mucosal-homing regulatory T cells in response to local inflammatory challenge. We provide evidence that the principal target for maternal treatment effects was the fetal dendritic cell progenitor compartment, equipping the offspring for accelerated functional maturation of the airway mucosal dendritic cell network following birth. These data provide proof of concept supporting the rationale for developing transplacental immune reprogramming approaches for primary disease prevention.
\end{abstract}

\section{Introduction}

A series of prospective birth cohort studies on the children of European traditional farming families $(1,2)$, now replicated in US studies contrasting Amish and Hutterite farming populations (3), have identified striking asthma-protective properties of oral and inhalation exposure to benign microbial stimuli present in dusts from farm barns. The target for these exposures in the offspring appears to be the innate immune system, and involves modulation of both immunoregulatory and effector cell function(s) (3-6) resulting in markedly reduced susceptibility to the asthma-promoting effects of common respiratory allergies. The temporal window during which these environmental stimuli exert their immunomodulatory effects spans the period when the developing immune system is undergoing postnatal functional maturation, but susceptibility to these effects also appears particularly high during prenatal development as demonstrated by the strong impact of maternal microbial exposures during pregnancy on ensuing asthma resistance in the offspring $(1,7)$.

Authorship note: PGH and DHS are co-senior authors

Conflict of interest: CP is an employee of OM Pharma (Vifor Pharma). CP had no input into data analysis or interpretation.

Submitted: June 1, 2018; Accepted: August 23, 2018

Reference information: J Clin Invest. 2018;128(11):4856-4869.

https://doi.org/10.1172/JCl122631.
A broad forerunner literature supports the general principle that maternal microbial exposures can result in transmission of transplacental signals that influence the functional phenotype of the developing fetal immune system (8-10), but these studies have focused almost exclusively on maternal infections, and usually on deleterious effects thereof. In contrast, in light of the findings from the farming family studies above $(1,7)$, we posit that benign environmental microbial exposures during pregnancy can be read out by the maternal mucosal immune surveillance system and transcribed into positive "immune training" signals for transplacental transmission to the developing offspring, equipping them for more rapid adaptation after birth to the microbe-rich postnatal environment. Moreover, we posit that this natural mechanism can be harnessed therapeutically; notably, if these benign environmental exposure effects could be reproduced by an agent that could be safely administered during pregnancy, it could open up novel possibilities for primary prevention of asthma. With this in mind we have recently completed a proof-of-concept study in pregnant mice with a microbial-derived therapeutic product, OM-85, which has been in widespread use in Europe in human infants and adults for more than 30 years for the boosting of resistance to airway inflammation and attendant wheezing symptoms associated with lower respiratory infections (11-15). In initial investigations to establish the safety of OM-85 use during preg- 
nancy, we demonstrated that maternal treatment with this agent enhanced homeostatic control of innate immune and inflammatory functions in gestational tissues at baseline and in the face of challenge with microbial pathogens including live influenza infection and the bacterial mimic lipopolysaccharide. Specifically, OM-85 treatment attenuated inflammatory symptoms (which are typically exaggerated during pregnancy) and protected against fetal growth restriction and/or pregnancy termination, which can follow maternal infection (16). In the study presented here we focus on the effects of maternal OM-85 treatment during healthy pregnancy on the immunocompetence of offspring during the postnatal weanling period when immune functions are typically developmentally compromised. In this regard, we focus on the effects of maternal OM-85 treatment on the capacity of offspring to regulate airway inflammatory responses associated with development of experimental atopic asthma during the weanling period, which in humans represents the age range at highest risk for initiation of what can be lifelong asthma (17).

\section{Results}

Experimental model of allergic airway inflammation in sensitized weanling mice: study rationale. For this study we used an experimental system developed for induction of Th2-associated cell-mediated inflammation in the conducting airway mucosa in adult rodents, as a model for the main lesional site in human asthma. Additional (albeit less extensive) inflammation also develops in peripheral lung tissue, but the relative contribution of this to airflow limitation in the asthmatic state is uncertain. The principal features of this model, focusing mainly on the airway mucosa, are illustrated in Supplemental Figure 1A; supplemental material available online with this article; https://doi.org/10.1172/ JCI122631DS1. Aeroallergen delivered to the airways of presensitized animals via large-droplet aerosol is captured by resident mucosal dendritic cells (DCs) that are functionally quiescent in the steady state (as marked by low to modest murine major histocompatibility complex class II [IAIE] expression) and are specialized for antigen sampling only, which they subsequently transport to airway draining lymph nodes (ADLNs) for presentation to allergen-specific memory $\mathrm{T}$ cells (18-20). The resultant $\mathrm{T}$ cell response generates a mixture of effector-memory $\mathrm{T}$ cells $\left(\mathrm{T}^{\mathrm{m}} \mathrm{effs}\right)$ and regulatory $\mathrm{T}$ cells (Tregs) in proportions determined via DC programming. Representatives of these populations traffic back to the airway mucosa, where they encounter resident mucosal DCs that have recently acquired aeroallergen, and bidirectional interactions between these 3 cell populations in situ determine the intensity and duration of the ensuing T cell-dependent inflammatory response within the airway mucosa $(21,22)$. In particular, the capacity for local activation of incoming $\mathrm{T}^{\mathrm{m}} \mathrm{effs}$ is limited via the suppressive effects of Tregs on surface IAIE and CD86 expression by mucosal conventional DCs (cDCs) $(18,22-24)$.

The principal DC population involved comprises the network of cDCs within the airway mucosa that are responsible for the major aspects of local immune surveillance (18). Plasmacytoid DCs (pDCs) have also been implicated in this process (25), particularly in relation to pathogen surveillance (26). The airway mucosal cDC population has the property of uniquely rapid turnover in the steady state, with $85 \%$ of the resident population turning over every approximately 24 hours, being continuously depleted by migration of antigen-bearing cells to ADLNs and simultaneously replenished via incoming precursors recruited from bone marrow (27). This orderly and highly dynamic process is rapidly accelerated during airway challenge events, during which cDC numbers can expand markedly within the airway epithelium and ADLNs $(18,28-30)$. This airway mucosal cDC network is developmentally compromised in immature humans $(31,32)$ and experimental animals $(33,34)$, and this partially explains the high risk of respiratory infections and aeroallergen sensitization associated with the infant period (35). Our hypothesis underlying this murine study is that maternal OM-85 treatment during pregnancy can enhance the functional maturation of this mucosal immune surveillance system in the offspring and, as a result, reduce susceptibility to initiation of inflammatory airway disease during the high-risk early postnatal period.

To test this hypothesis, we used a variant of the above-mentioned allergic airway inflammation model, modified from earlier studies assessing farm-related exposures (36), involving sensitization of 21-day-old weanling BALB/c mice to ovalbumin (OVA) using a prime-boost schedule followed by subsequent airway challenge with aerosolized OVA (Supplemental Figure 1, B and C). Details of the ensuing response are discussed below.

Aeroallergen-induced cellular response in the airways: baseline characteristics. Sensitized animals displayed high levels of OVA-specific serum IgE 24 hours after repeated OVA aerosol challenge (Figure 1A). The challenged animals displayed gross hypertrophy of ADLNs involving, in particular, T cells (see below), which was accompanied by intense inflammatory cell infiltration into the airways encompassing eosinophils, neutrophils, and lymphocytes detectable by bronchoalveolar lavage (Figure 1B), increased levels of Th2 cytokines in lung homogenates (not shown), and airway hyperresponsiveness manifesting as increased airway resistance to methacholine (MCh) (Figure 1C).

Further characterization of the phenotype of the cellular response within the airway compartment by multicolor flow cytometry (see Methods for gating strategies) revealed significant increases in the total cellularity of parathymic and mediastinal ADLNs and trachea, with no observable difference in peripheral lung (Supplemental Figure 1D). This cellular response was dominated by changes in the $\mathrm{CD}^{+} \mathrm{T}$ cells (Supplemental Figure $1 \mathrm{E}$ ) and especially the $\mathrm{CD} 4^{+} \mathrm{T}$ cell compartment (Supplemental Figure $1 \mathrm{~F}$ ). These changes in particular involved increases in the numbers (Supplemental Figure 1G), proportions (Figure 1D), and activation status (Figure 1, E and $\mathrm{F}$ ) of $\mathrm{CD}^{+} \mathrm{CD} 4^{+} \mathrm{CD} 25^{+} \mathrm{FoxP} 3^{-}$ $\mathrm{T}^{\mathrm{m}}$ effs within the ADLNs and in tracheal tissue, with much smaller parallel changes in peripheral lung parenchyma (Figure 1D), which is consistent with deposition of the bulk of aerosol droplets in the large and central airways. ADLN T ${ }^{\mathrm{m}}$ effs displayed a heightened state of activation (Figure 1E), whereas lung and especially tracheal $\mathrm{T}^{\mathrm{m}}$ effs demonstrated high levels of Ki67 expression suggesting very recent (possibly local) proliferation (Figure 1F; see corresponding $\mathrm{CDC}$ data below). In conjunction with the $\mathrm{CD} 25^{+}$ FoxP3 ${ }^{-} \mathrm{T}^{\mathrm{m}}$ eff response, a decrease in $\mathrm{CD}^{+} \mathrm{CD}^{+} \mathrm{CD}^{2} 5^{+} \mathrm{FoxP}^{+}$ Tregs within the $\mathrm{T}$ cell compartment of ADLNs was observed, accompanied by a large increase within trachea and a smaller (but significant) increase in peripheral lung tissues (Figure 1G), pre- 

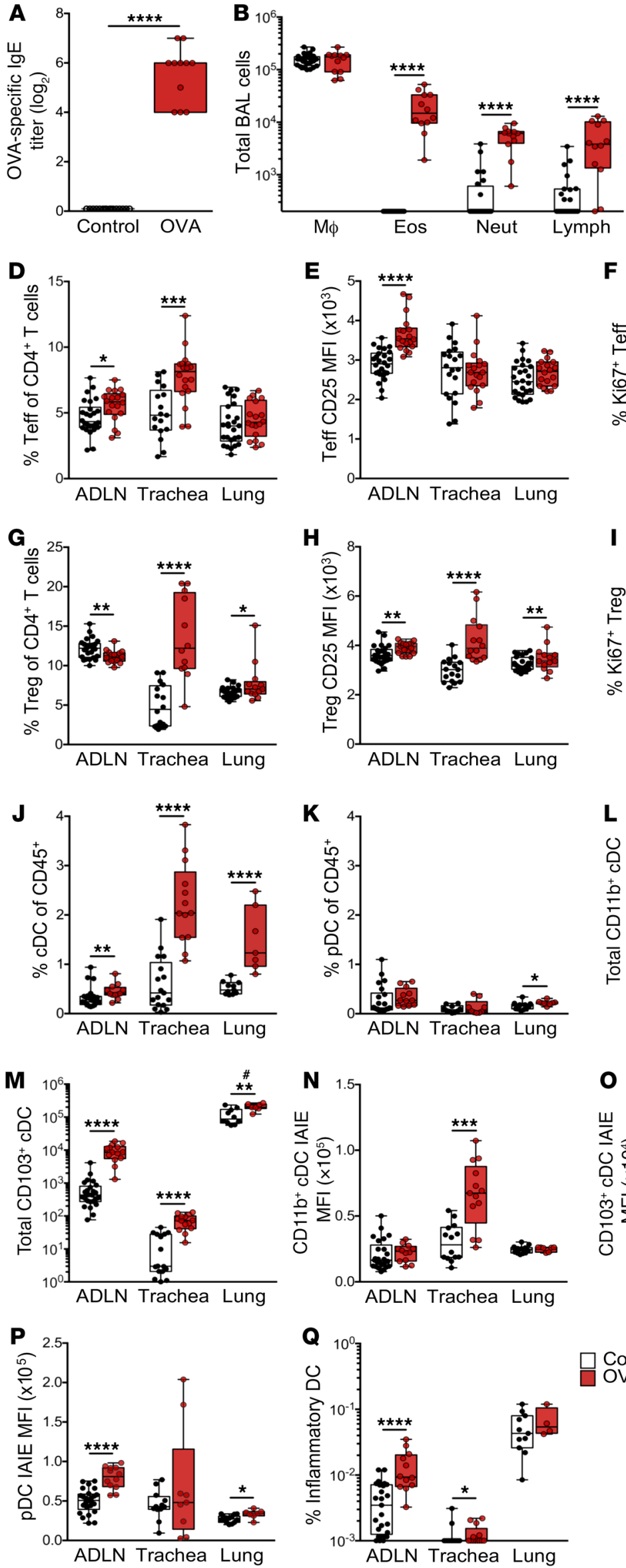

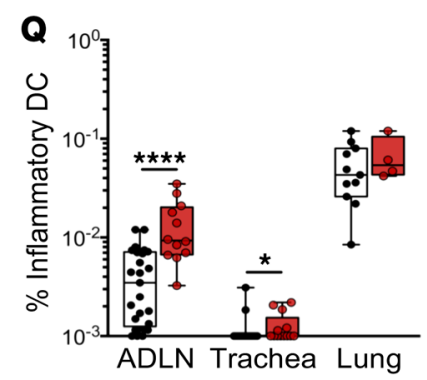

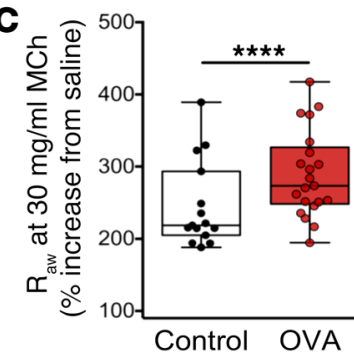
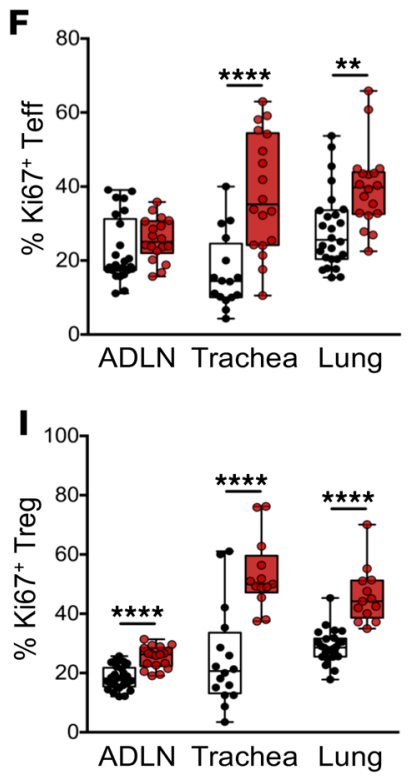

Figure 1. Response in early life sensitizes mice to aeroallergen challenge. (A) Serum titers of OVA-specific IgE as measured by in vivo passive cutaneous anaphylaxis assay. (B) Absolute numbers of macrophages (M $\phi)$, eosinophils (Eos), neutrophils (Neut), and lymphocytes (Lymph) as determined by bronchoalveolar lavage (BAL) 24 hours after challenge. (C) Airway hyperresponsiveness to $M C h$ challenge using $30 \mathrm{mg} / \mathrm{ml} \mathrm{MCh}$. (D-F) Analysis of $\mathrm{CD}^{+}{ }^{+} \mathrm{CD} 4{ }^{+} \mathrm{CD}_{25}{ }^{+} \mathrm{FoxP3}-$

effector T cells (Teffs) within airway tissues (ADLNs, trachea, and peripheral lung) showing (D) Teffs as a proportion of CD4 ${ }^{+} \mathrm{T}$ cells, (E) mean fluorescence intensity (MFI) of CD25 on Teffs, and (F) the proportion of Ki67+ Teffs. (G-I) Analysis of $\mathrm{CD}^{+}{ }^{+} \mathrm{CD} 4{ }^{+} \mathrm{CD} 25^{+} \mathrm{FoxP3}^{+}$Tregs within airway tissues showing (G) Tregs as a proportion of total CD4 T cells, (H) MFI of CD25 on Tregs, and (I) the proportion of $\mathrm{Ki}^{+} 7^{+}$Tregs. (J) IAIE+F4/80-CD11 ${ }^{+} \mathrm{CDC}$ s and (K) IAIE+Ly6C/Clo/+F4/80-CD11C ${ }^{+}$CD11b B220 ${ }^{+}$pDCs as a proportion of total CD45 ${ }^{+}$leukocytes in airway tissue samples. (L and $\mathbf{M}$ ) Absolute numbers of (L) $\mathrm{CD}_{11 b^{+}}$and $(\mathrm{M}) \mathrm{CD} 103^{+}$ cDCs within airway tissue samples. (N-P) MFI of IAIE expression on (N) $\mathrm{CD} 1 \mathrm{~b}^{+} \mathrm{cDCs},(\mathbf{0}) \mathrm{CD} 103^{+} \mathrm{cDCs}$, and

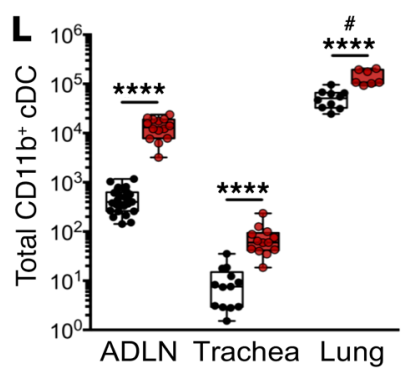

(P) pDCs within airway tissue samples. (Q) Proportion of inflammatory DCs within airway tissue samples. Data are presented from individual animals comparing naive controls (white) versus OVA-sensitized and aerosol-challenged offspring (with sample collection 24 hours after challenge; red) and displayed as box-and-whisker plots showing median, first quartile $(\underline{O})$, and third quartile $\left(Q_{3}\right)$ and minimum to maximum values of $n \geq 6$ independent experiments. "Total peripheral lung cells data are displayed as cells per milligram of tissue ( $\mathbf{L}$ and M). Statistical significance was determined using Student's $t$ test or Mann-Whitney $U$ test (A, B, and E-Q) or 2-way ANOVA followed by Sidak's multiple comparisons test (C) and is presented as ${ }^{*} P<0.05$, ${ }^{*} P<0.01,{ }^{* *} P<0.001$, and ${ }^{* * * *} P<0.0001 . R_{a w}$, airway

Contro OVA resistance. 

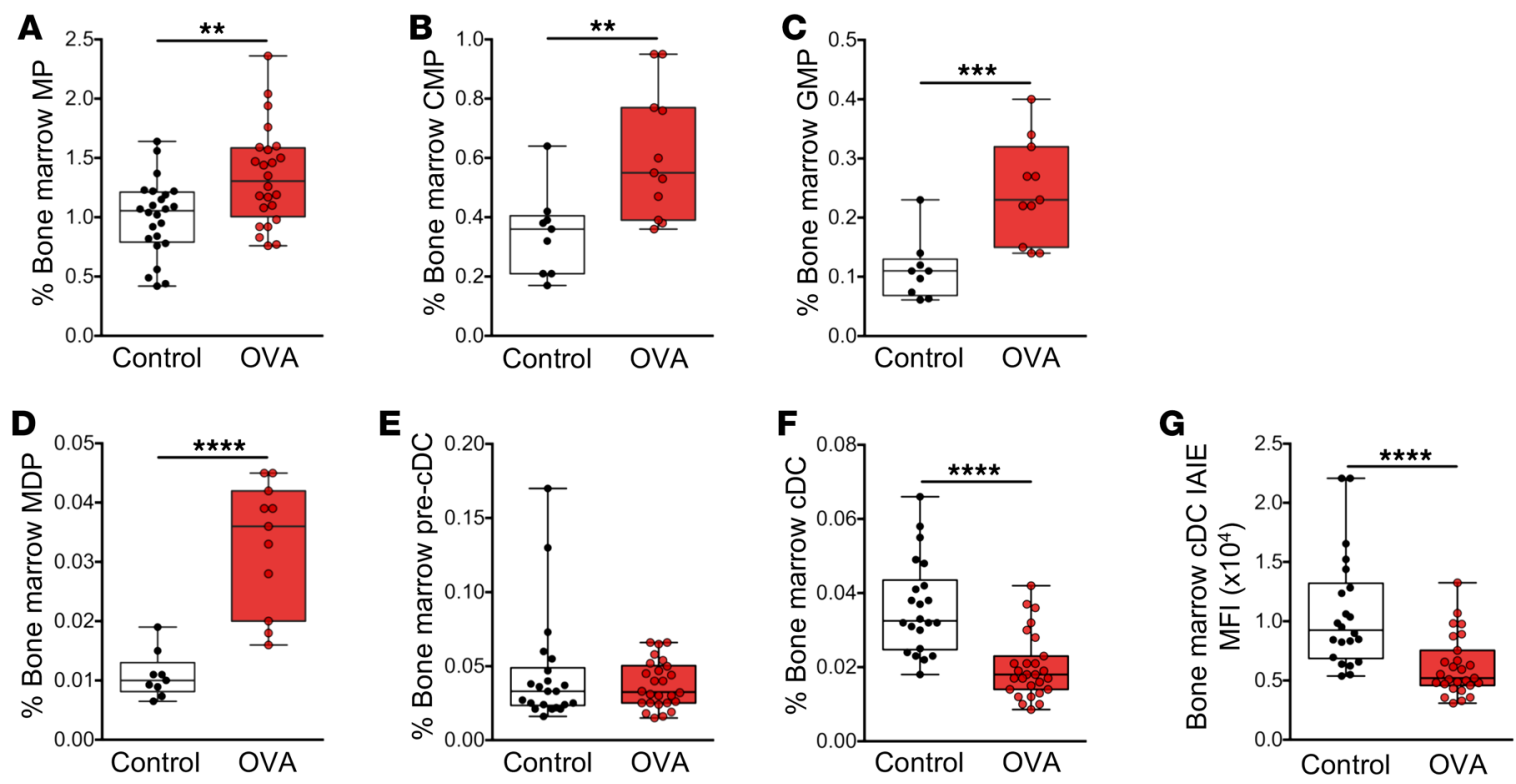

Figure 2. Bone marrow cellular response following aeroallergen challenge in mice sensitized at weaning. (A) Lin-IL7-R $\alpha^{-} C^{-K i t^{+}} S c a-1^{-}$myeloid progenitors

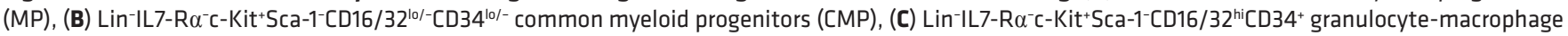

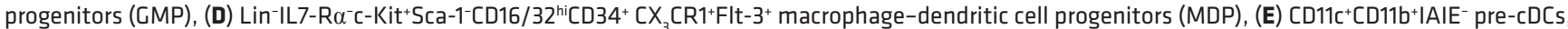
and (F) CD11 $\mathrm{C}^{+} \mathrm{CD} 11 \mathrm{~b}^{+} \mid \mathrm{AIE}^{+} \mathrm{CDCs}$ in bone marrow as a proportion of total cells. (C) MFI of IAIE on bone marrow cDCs. Data are presented from individual animals comparing naive controls (white) versus OVA-sensitized and aerosol-challenged offspring (with sample collection 24 hours after challenge; red). Data are displayed as box-and-whisker plots showing median, $O_{1}$, and $O_{3}$ and minimum to maximum values of $n \geq 8$ independent experiments. Statistical significance was determined using Student's $t$ test or Mann-Whitney $U$ test and is presented as ${ }^{* *} P<0.01,{ }^{* * *} P<0.001,{ }^{* * * *} P<0.0001$.

sumably derived by migration of these cells from ADLNs. Characterization of Treg function-associated markers revealed increased CTLA- $4^{+}$Tregs within trachea $(74.47 \% \pm 3.78 \%$ vs. $46.41 \% \pm$ $6.05 \%)$ and peripheral lung $(51.16 \% \pm 2.50 \%$ vs. $34.9 \% \pm 2.54 \%)$ compared with naive controls (Supplemental Figure 1H). Furthermore, an increase in $\mathrm{CD} 69^{+}$Tregs was identified within peripheral lung samples $(15.68 \% \pm 0.53 \%$ vs. $12.98 \% \pm 1.54 \%)$, while CD $69^{+}$ Tregs were reduced within the ADLNs $(28.19 \% \pm 0.69 \%$ vs. $32.5 \%$ $\pm 1.19 \%$ ) compared with naive controls (Supplemental Figure 1I). Airway Tregs additionally displayed enhanced CD25 expression (Figure 1H) and proliferative capacity (Figure 1I) following OVA challenge compared with naive controls.

Forerunner studies from our laboratory $(18,22,37)$ suggest that in the early stage of recall responses to inhaled antigen, the limiting factor determining the efficiency of generation of airway mucosal homing Tregs is the efficiency of DC-mediated transport of antigen-specific signals from the airway to ADLNs. We therefore turned our attention to characterizing the myeloid cell populations localized within the airways of early-life OVA-sensitized and aerosol-challenged animals. For these analyses, $\mathrm{IAIE}^{+} \mathrm{F} 4 / 80^{-} \mathrm{CD} 11 \mathrm{c}^{+}$ cDCs were subdivided into $\mathrm{CD}^{-1} \mathrm{~b}^{+} \mathrm{CD}^{-103^{-}}$and $\mathrm{CD} 11 \mathrm{~b}^{-} \mathrm{CD}^{-} \mathrm{3}^{+}$ populations, representing the 2 dominant $\mathrm{CDC}$ subsets localized within the airways, with specialized roles in immunogenic and tolerogenic responses, respectively (38). We additionally quantified $\mathrm{IAIE}^{+} \mathrm{Ly} 6 \mathrm{G} / \mathrm{C}^{\mathrm{lo} /}+\mathrm{F} 4 / 80^{-} \mathrm{CD} 11 \mathrm{c}^{+} \mathrm{B} 22 \mathrm{O}^{+} \mathrm{CD} 11 \mathrm{~b}^{-}$pDCs, which represented a much smaller proportion of the $\mathrm{CD} 45^{+}$population compared with cDCs (Figure 1, J and K). Consecutive aerosol challenges of presensitized mice induced a minor response in pDCs in peripheral lung only (Figure 1K), in contrast to a significant influx of both cDC subsets across all airway tissues sampled, in particular the tracheal mucosa and its ADLN, where numbers of these cells displayed a log-fold increase (Figure 1, L and M). Characterization of cDCs based on expression levels of surface IAIE demonstrated marked enhancement in expression intensity across the entire cDC population within the trachea following challenge (Figure 1, $\mathrm{N}$ and $\mathrm{O}$ ). This observation is consistent with allergen-driven functional maturation in situ of these cells from strict antigen-sampling to antigen-presentation phenotype as previously observed (18, 19), and this provides a plausible mechanism for local activation of $\mathrm{T}^{\mathrm{m}}$ effs within the mucosa during repeated challenge (Figure 1, $\mathrm{D}$ and $\mathrm{F}$ ). In parallel, ADLNs displayed modest IAIE upregulation in the $\mathrm{CD}_{103}{ }^{+}$subset, while both subsets remained at baseline in the peripheral lung (Figure 1, N and O). Furthermore, upregulation of pDC IAIE expression occurred both in ADLNs and in peripheral lung (Figure 1P). Additionally, we observed increased numbers after challenge of rare $\mathrm{IAIE}^{+} \mathrm{F} 4 / 80^{\text {int }} \mathrm{Ly} 6 \mathrm{G} / \mathrm{C}^{\text {hi }} \mathrm{CD} 11 \mathrm{~b}^{+}$ CD11 $\mathrm{c}^{+}$inflammatory DCs, which have been implicated in driving Th2-mediated inflammation in response to antigen exposure (39, 40), within ADLNs and tracheal tissue (Figure 1Q).

Role of the bone marrow in the development of an experimental allergic airway inflammatory response. The granulocytic and DC subsets identified above as participants in the airway response to aerosol challenge in sensitized mice are derived from bone marrow, and we posited that (as inferred from earlier studies on eosinophils in aeroallergen-challenged human asthmatics; ref. 41) the dynamic changes detailed in these populations in our murine model of allergic airway inflammation above should be mirrored by changes in respective bone marrow precursor populations.

The scheme in Supplemental Figure 2 summarizes current understanding of the interrelationships among relevant bone 
A

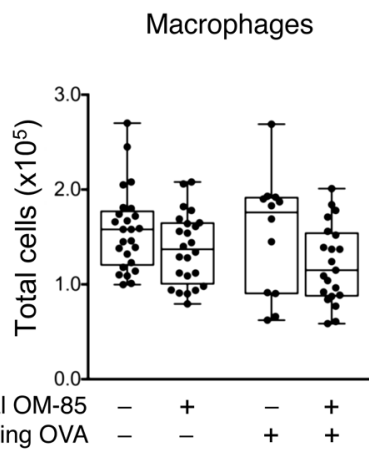

B

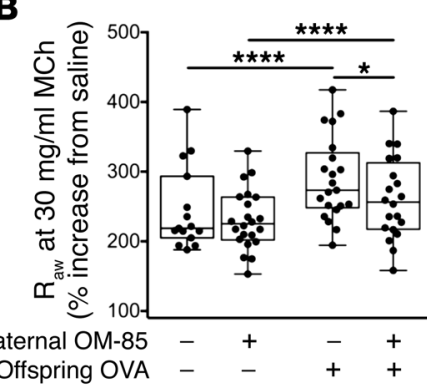

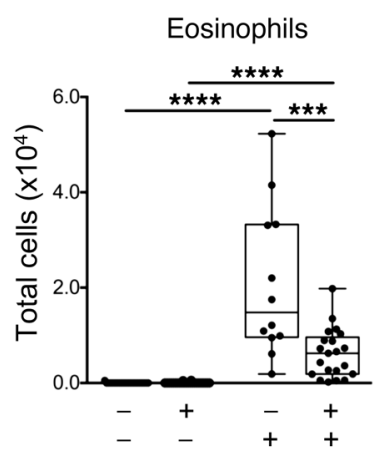

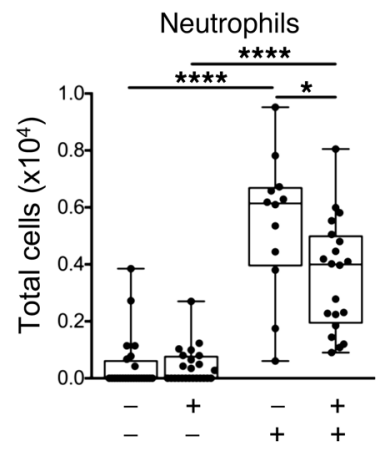

Lymphocytes

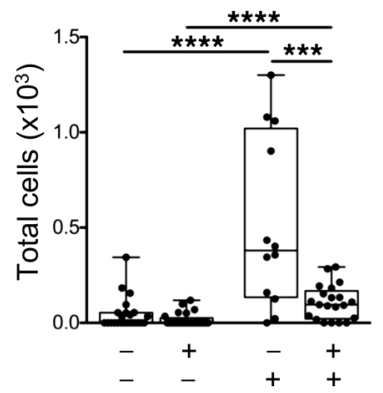

\begin{abstract}
Figure 3. Maternal $0 \mathrm{M}-85$ treatment during pregnancy confers resistance to airway inflammation in sensitized and challenged offspring. (A) Absolute numbers of macrophages, eosinophils, neutrophils, and lymphocytes within BAL 24 hours after challenge. (B) Airway hyperresponsiveness to $30 \mathrm{mg} / \mathrm{ml} \mathrm{MCh}$ challenge. Data are presented from individual animals comparing naive controls versus OVA-sensitized and aerosol-challenged offspring from $0 \mathrm{M}-85$-treated and untreated mothers and displayed as boxand-whisker plots showing median, $\underline{Q}_{1}$, and $\underline{Q}_{3}$ and minimum to maximum values of $n \geq 6$ independent experiments. Statistical significance was determined using Student's $t$ test (A) or 2-way ANOVA followed by Sidak's multiple comparisons test (B) and is presented as ${ }^{*} P<0.05$, ${ }^{* *} P<0.001$, ${ }^{* * *} P<0.0001$.
\end{abstract}

marrow progenitor compartments in the developmental pathway that leads to production of granulocytes, pDCs, and cDCs. We assessed the impact of repeated challenge with aeroallergen on the size of relevant compartments at or beyond the myeloid progenitor (MP) stage, using multicolor flow cytometry, targeting the markers shown. These analyses (Figure 2, A-D) demonstrated first that early myeloid precursor compartments up to and including the granulocyte-macrophage progenitor (GMP) population, which are a major source of both DC and granulocyte populations $(42,43)$, and the macrophage-dendritic cell progenitor (MDP) compartment, which is committed to $\mathrm{pDC}$ and $\mathrm{CDC}$ production (44-46), expand significantly in response to repeated aeroallergen challenge of sensitized animals. This finding is consistent with the data shown in Figure 1, demonstrating the buildup of these populations in the challenged airways. Beyond this stage, while no changes were observed in the pre-cDC compartment (Figure $2 \mathrm{E}$ ), the $\mathrm{cDC}$ compartment appeared reduced relative to baseline (Figure 2F), and this may be expected in light of the accumulation of these cells in tracheal mucosa and at their ultimate destination in the ADLN, which displayed a log-fold increase in $\mathrm{CDC}$ numbers after challenge (Figure 1, $\mathrm{L}$ and $\mathrm{M}$ ).

Furthermore, cDCs remaining within the bone marrow after challenge displayed reduced IAIE surface expression relative to baseline controls (Figure $2 \mathrm{G}$ ), which may indicate preferential recruitment of $\mathrm{cDCs}$ from the more functionally mature end of the developmental spectrum.

Maternal OM-85 treatment during pregnancy: effects on experimental allergic airway inflammation susceptibility in sensitized offspring. We posited that treatment of pregnant mice with the microbial-derived immunomodulatory agent OM-85 would enhance the resistance of their offspring to development of allergic airway inflammation during the early postweaning period. To test this hypothesis, we used an OM-85 treatment protocol we have recently demonstrated to protect pregnant mice and their fetuses against the toxic effects of bacterial and viral infections (16), comprising oral administration of OM-85 from gestation day 9.5 to 17.5 , followed by natural delivery of offspring 2-3 days later. Age-matched offspring from OM-85-treated and untreated control mothers were sensitized at weaning (21 days of age) and aerosol-challenged as shown in Supplemental Figure 1, B and C, and their airway responses compared (Figure 3). As previously demonstrated, early-life OVA sensitization and ensuing aerosol challenge initiate granulocytic and lymphocytic infiltration of the airways, and these cellular responses (Figure 3A), together with accompanying development of airway hyperresponsiveness to MCh (Figure 3B), were markedly attenuated in the offspring of mice treated during pregnancy. Notably, treatment did not affect OVA-specific IgE levels ( $\log _{2}$ titers 5.44 \pm 0.21 and $5.54 \pm 0.34$ in treated vs. untreated groups, respectively), implying that OM-85 treatment influences mechanism(s) downstream of sensitization per se.

Treg function in offspring as a potential target for maternal OM-85 treatment effects. Previous studies from our laboratory and others have identified mucosal homing Tregs as a potential target for OM-85-mediated treatment effects in adult nonpregnant $(47,48)$ and pregnant $(16)$ animals, prompting an initial focus on this population. We accordingly phenotyped the $\mathrm{T}$ cell response within the airway compartment using multicolor flow cytometry. The magnitude of the overall $\mathrm{CD} 4^{+} \mathrm{T}$ cell response to OVA aerosol was reduced in the treatment group, particularly in the tracheal mucosa (Figure 4, A and B). Following challenge, the proportion of Tregs within the ADLN CD4 ${ }^{+} \mathrm{T}$ cell population declined in both groups (Figure 4C) and correspondingly increased in respective tracheal tissues (Figure 4F), consistent with their migration to the airway mucosal challenge site. However, both the proportional decline in Tregs in ADLNs and the corresponding increase in trachea were significantly higher in the OM-85 treatment group (Figure $4 \mathrm{~F}$ ). Treg/ $\mathrm{T}^{\mathrm{m}}$ eff ratios after challenge remained higher in ADLNs in offspring from treated mothers (Figure 4E) but did 
A
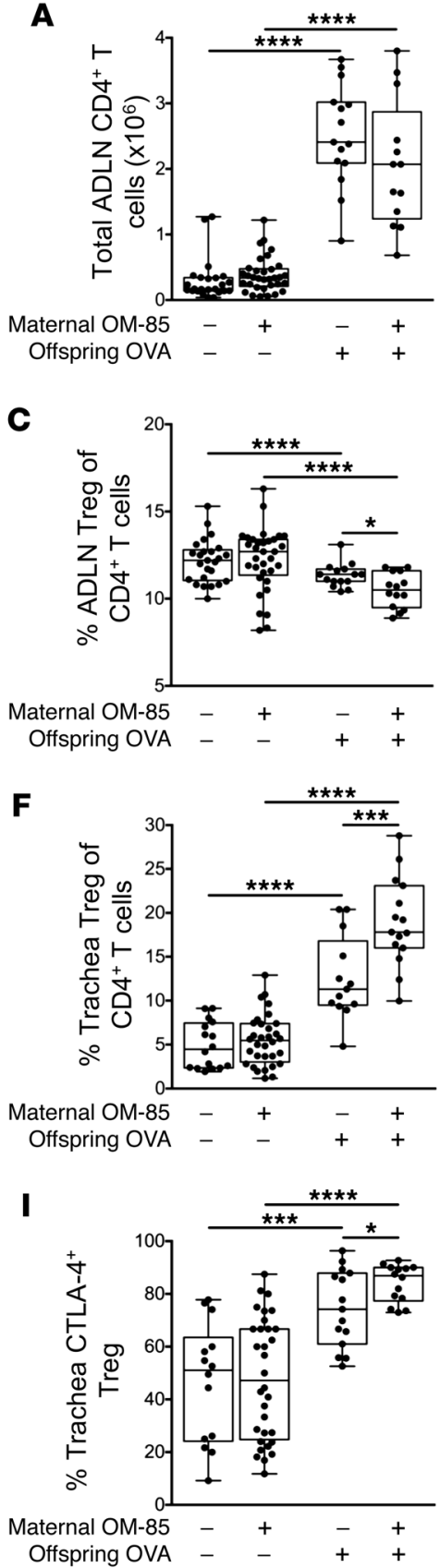

B
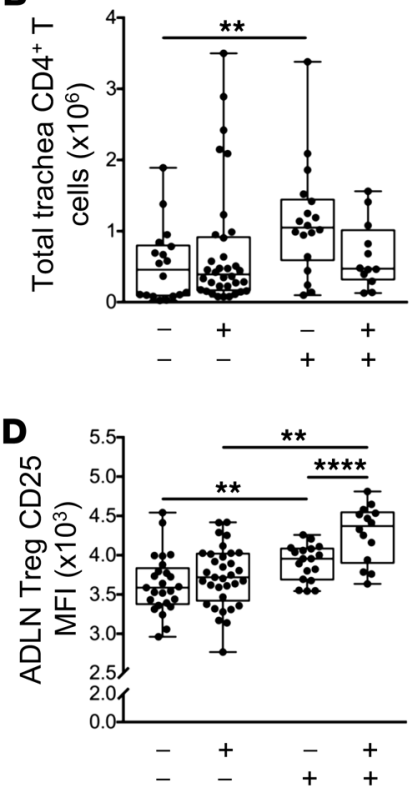

G

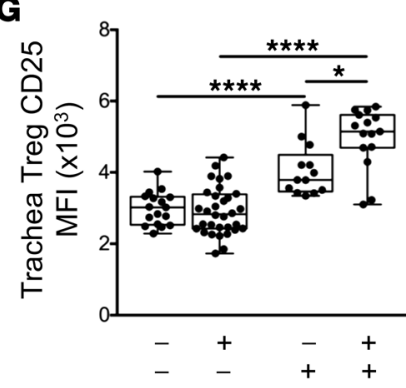

J

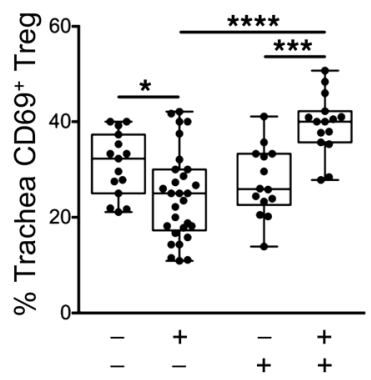

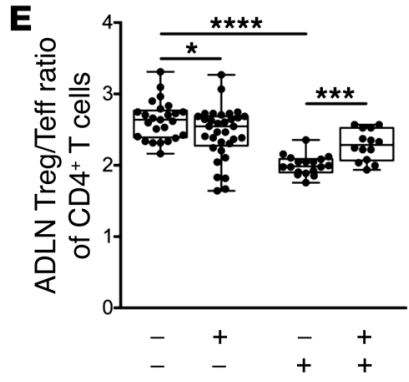

H

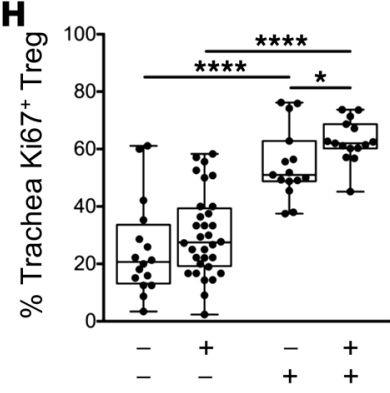

$\mathbf{K}$

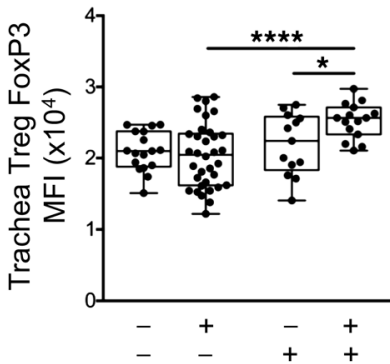

Figure 4. Maternal OM-85 treatment during pregnancy promotes Treg suppressive phenotypes in sensitized and challenged offspring. ( $A$ and $B$ ) Absolute numbers of $\mathrm{CD3}^{+}$ CD4 ${ }^{+}$CD8 $^{-}$T cells in (A) ADLNs and (B) trachea. (C-E) Analysis of Tregs within ADLNs showing (C) Tregs as a proportion of total CD4 ${ }^{+} \mathrm{T}$ cells, (D) MFI of CD25 on Tregs, and (E) Treg/Teff ratio within total $\mathrm{CD} 4^{+} \mathrm{T}$ cells. (F-J) Analysis of Tregs in the trachea showing (F) Tregs as a proportion of total $\mathrm{CD}^{+} \mathrm{T}$ cells, (G) MFI of CD25 on Tregs, (H) the proportion of Ki67+ Tregs, (I) the proportion of CTLA-4+ $4^{+}$Tregs, and (J) the proportion of $\mathrm{CD69}+$ Tregs. (K) MFI of FoxP3 on tracheal Tregs. Data are from individual animals and compare naive controls versus OVA-sensitized and aerosol-challenged offspring from $0 \mathrm{M}-85$-treated and untreated mothers. Data are displayed as box-and-whisker plots showing median, $\underline{Q}_{1}$, and $\underline{O}_{3}$ and minimum to maximum values of $n \geq 9$ independent experiments. Statistical significance was determined using Student's $t$ test or Mann-Whitney $U$ test and is presented as ${ }^{*} P<0.05$, ${ }^{* *} P<0.01,{ }^{* * *} P<0.001$, ${ }^{* * * *} P<0.0001$. not differ significantly between the groups in trachea (data not shown). Furthermore, the relative expression levels of the Treg function-associated molecules CD25 (Figure 4G), CTLA-4 (Figure 4I), and FoxP3 (Figure 4K), along with the activation/proliferation-associated markers CD69 (Figure 4J) and Ki67 (Figure $4 \mathrm{H}$ ), were significantly elevated in tracheal Tregs from the treated group, consistent with activation and enhanced functionality. Similar patterns were also observed for Treg populations from peripheral lung tissues (Supplemental Figure 3).

Maternal OM-85 pretreatment modulates the functional phenotype of airway-associated DC populations in offspring. The accumulation of cDCs in airway-associated tissue compartments in response to airway challenge was generally reduced in the treated group, and these differences were statistically significant for
$\mathrm{CD}_{103}{ }^{+} \mathrm{cDCs}$ in the trachea, and for CD11b ${ }^{+} \mathrm{cDCs}$ in ADLNs and lung (Figure 5, A and B). However, the most notable finding was related to $\mathrm{CDC}$ maturational status as measured by surface IAIE expression, which was reduced at baseline in both $\mathrm{CD}_{103}{ }^{+}$and $\mathrm{CD}_{11 \mathrm{~b}^{+}}$subsets in ADLNs (Figure 5C). Moreover, the antigeninduced surge in IAIE expression levels on both subsets in the rapidly-turning-over cDC population in the tracheal mucosa, which is a hallmark of functional activation of these cells, was likewise attenuated (Figure 5D). This contrasted with the picture in the peripheral lung (Figure 5E), which is dominated by $\mathrm{cDC}$ populations with much longer half-lives, and which displayed minimal upregulation of IAIE in response to challenge. However, as noted above, aerosol challenge does elicit a small but significant increase in pDCs in peripheral lung tissue, and this response was attenuat- 

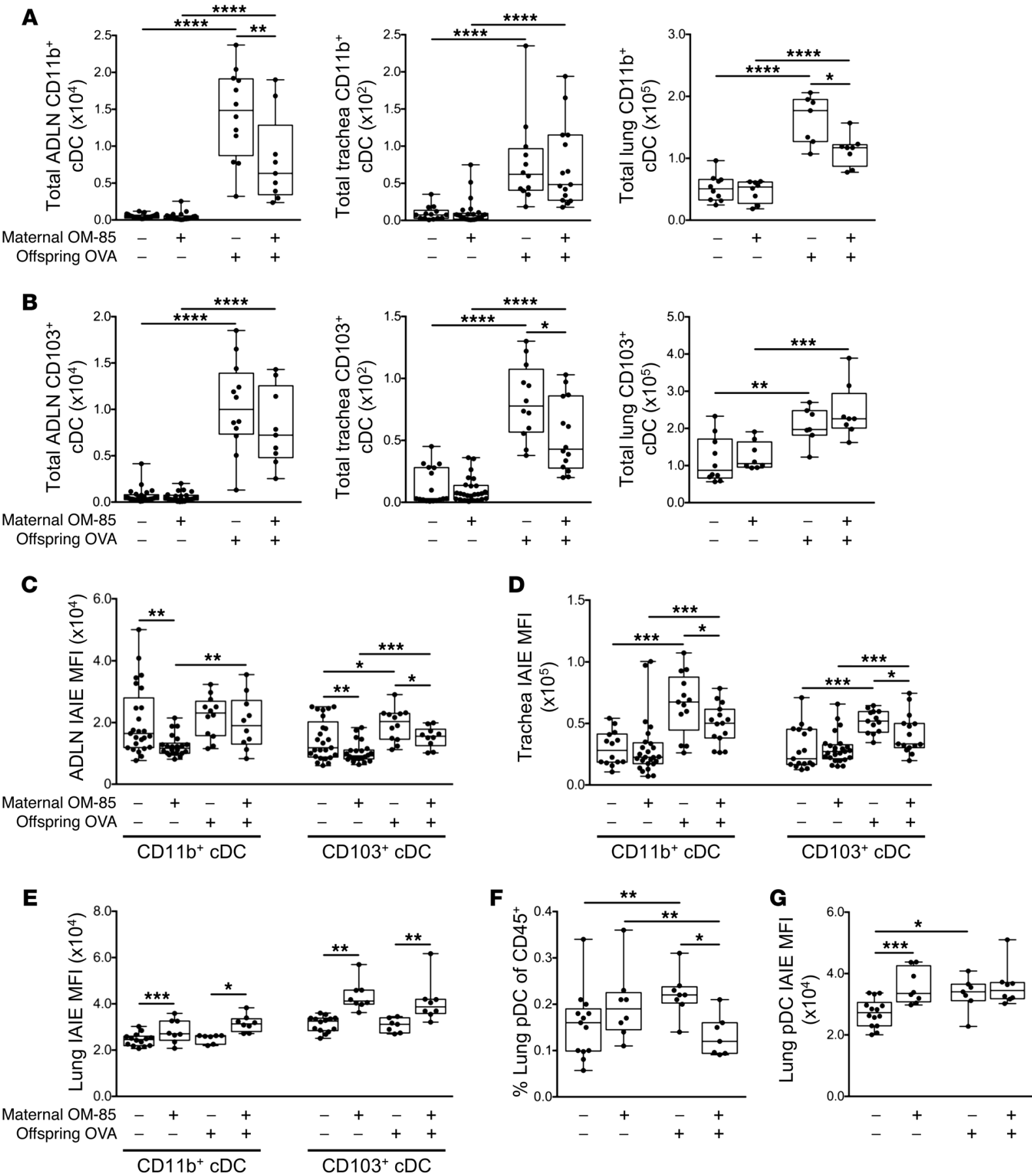

Figure 5. Treatment of mothers with $0 \mathrm{M-85}$ during pregnancy limits inflammatory airway mucosal DC responses in sensitized and aeroallergenchallenged offspring. (A) Absolute numbers of $\mathrm{CD}_{11 \mathrm{~b}^{+}}$and (B) $\mathrm{CD} 103^{+} \mathrm{CDCs}$ within ADLNs, trachea, and peripheral lung. (C-E) MFI of IAIE expression on (C) $\mathrm{CD} 1 \mathrm{~b}^{+}$and $\mathrm{CD} 103^{+} \mathrm{CDCs}$ within ADLNs, (D) trachea, and (E) peripheral lung. (F) Peripheral lung pDCs as a proportion of total CD45 cells. (C) MFI of IAIE on peripheral lung pDCs. Data are presented from individual animals comparing naive controls versus OVA-sensitized and aerosol-challenged offspring from $\mathrm{OM}-85$-treated and untreated mothers and displayed as box-and-whisker plots showing median, $\underline{Q}_{1}$, and $\underline{\underline{Z}}_{3}$ and minimum to maximum values of $n \geq 5$ independent experiments. Total peripheral lung cells displayed as cells per milligram of tissue (A and $\mathbf{B})$. Statistical significance was determined using Student's $t$ test or Mann-Whitney $U$ test and is presented as ${ }^{*} P<0.05,{ }^{* *} P<0.01,{ }^{* *} P<0.001,{ }^{* * * *} P<0.0001$.

ed in the treated group (Figure 5, F and G). We also screened the groups for treatment effects on the rare inflammatory DC subset in airway tissues; however, none were detected (data not shown).

Offspring bone marrow as the primary target for maternal OM-85 treatment effects. The final series of experiments tested the hypothesis that maternal OM-85 treatment-mediated effects on cellular immune function(s) in offspring respiratory tract tissues in this model may be associated with upstream effects on relevant precursor populations in bone marrow. Figure 6 directly compares the aeroallergen-induced bone marrow responses of offspring 

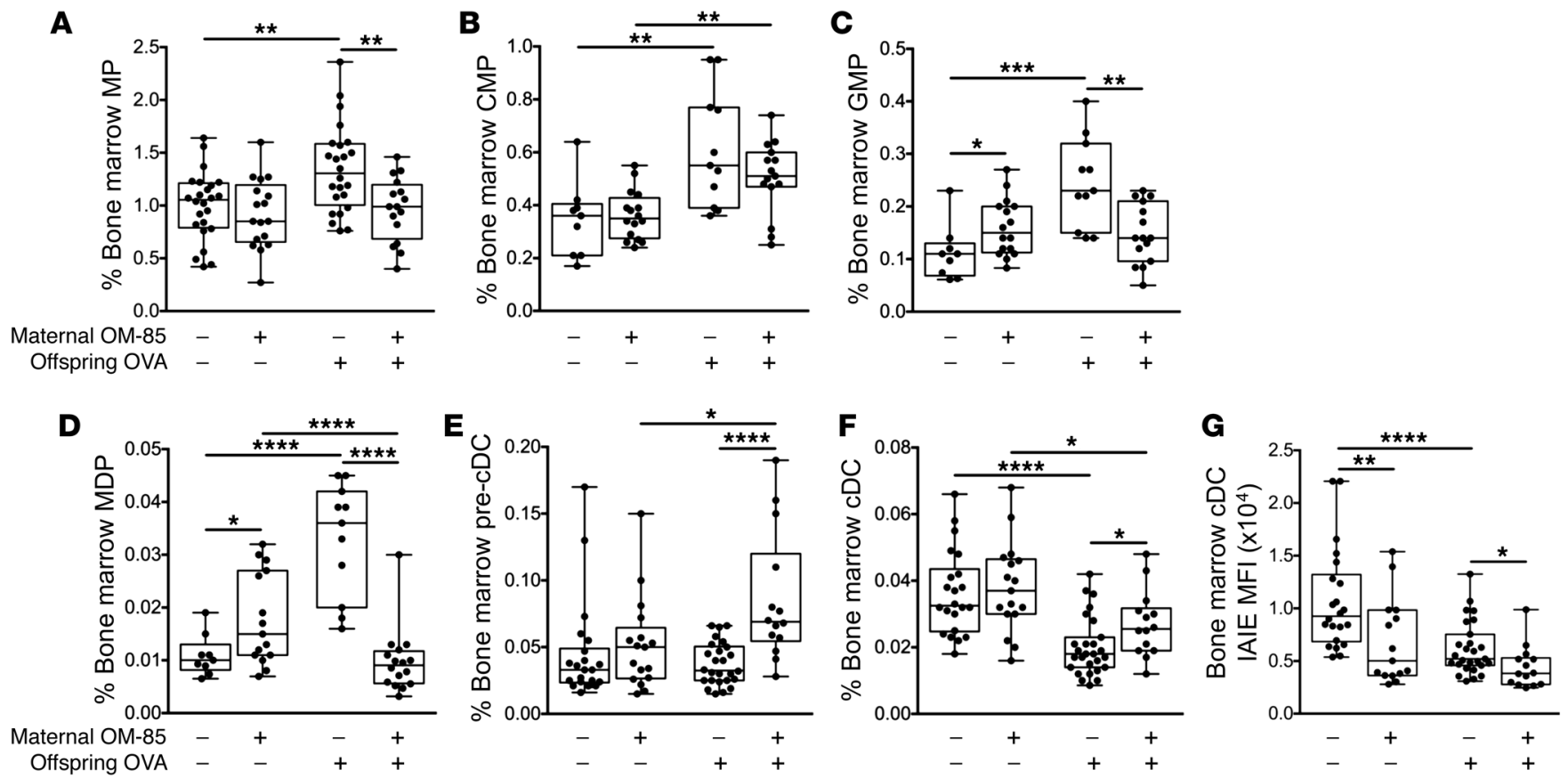

Figure 6. Treatment of mothers with 0M-85 during pregnancy alters ensuing responses in bone marrow cellular subpopulations. (A) MPs, (B) CMPs, (C) GMPs, (D) MDPs, (E) pre-cDCs, and (F) cDCs as a proportion of total cells. (C) MFI of IAIE expression on bone marrow cDCs. Data are presented from individual animals comparing naive controls versus OVA-sensitized and aerosol-challenged offspring from OM-85-treated and untreated mothers and displayed as box-and-whisker plots showing median, $\underline{Q}_{1}$, and $\underline{Q}_{3}$ and minimum to maximum values of $n=14$ independent experiments. Statistical significance was determined using Student's $t$ test or Mann-Whitney $U$ test and is presented as ${ }^{*} P<0.05$, ${ }^{* *} P<0.01,{ }^{* *} P<0.001,{ }^{* * * *} P<0.0001$.

from treated versus untreated mothers. Firstly, while baseline output of pre-cDCs and cDCs was comparable between groups, there were small but significant increases in the resting GMP and MDP populations in the control offspring from treated mothers (Figure 6, C and D). However, the major treatment-associated differences were revealed by aeroallergen challenge, notably a consistent attenuation of the expansion in all precursor compartments spanning the MP through MDP stages that was observed in the challenged offspring from untreated mothers (Figure 6, A-D). Secondly, at the end of this developmental spectrum, the post-challenge depletion of bone marrow cDC reserves that occurs in the offspring of untreated mothers was significantly attenuated (Figure 6, E and F), consistent with the reduced draw on this pool resulting from reduced recruitment to airway mucosa and ADLNs in the OM-85-treated group (Figure 5, A and B).

It is additionally pertinent to note that expression levels of IAIE on cDCs were reduced in the treated group both at baseline and, in particular, after challenge (Figure 6G), suggesting maintenance of a more tightly regulated/quiescent functional state, mirroring the picture seen for trachea and ADLN cDCs in Figure 5. A similar pattern was also observed in relation to the bone marrow pDC reservoir (data not shown).

Maternal OM-85 treatment effects at earlier ages. The data above pertain to animals sensitized at 3 weeks and challenged/sacrificed at 6 weeks. In the studies presented in Figure 7, we assessed the extent to which treatment effects on DC populations were demonstrable at younger ages. Looking first at age 3 weeks, we observed that the offspring of OM-85-treated mothers displayed higher numbers of $\mathrm{CD}_{11 \mathrm{~b}^{+}}$and $\mathrm{CD} 103^{+} \mathrm{cDCs}$ in lung tissue at baseline
(Figure 7, A and B) and higher levels of attendant IAIE expression (Figure 7C), consistent with treatment-mediated acceleration of postnatal maturation of DC networks in the respiratory tract. In a preliminary experiment we also compared total $\mathrm{CDC}$ yields in granulocyte-macrophage colony-stimulating factor-driven (GM-CSF-driven) bone marrow cultures derived from the same animals, and the increased yields from the treated group (Figure 7D) again point to the marrow as the likely primary site of action of maternal OM-85 treatment.

To further extend this finding, we characterized the progenitor pool within freshly harvested fetal bone marrow at 18.5 days gestation, 24 hours after the last maternal OM- 85 oral dose. The marked increase in total bone marrow cDCs (Figure 7E) accompanied by parallel expansion in the upstream MDP compartment in the treated group (Figure 7F) is consistent with the conclusion that the bone marrow is the ultimate target for OM- 85 treatment effects.

OM-85-mediated attenuation of the responsiveness of bone marrow $D C$ precursors to environmental inflammatory stimuli: validation of $O M-85$ treatment effects in an independent inflammatory model. In the experiments illustrated in Figure 8, we cultured bone marrow from 6-week-old offspring of OM-85-treated and untreated mothers in GM-CSF-enriched medium for 7 days, adding the archetypal proinflammatory agent bacterial lipopolysaccharide (LPS) to half the cultures for the last 24 hours. Comparison of resultant activation levels of cDCs by surface expression of IAIE (Figure 8A) and the costimulator CD86 (Figure 8B) indicated marked attenuation of upregulation of these function-associated markers, consistent with enhanced capacity for homeostatic regulation of inflammatory responses in general in cDCs from the treated group. 

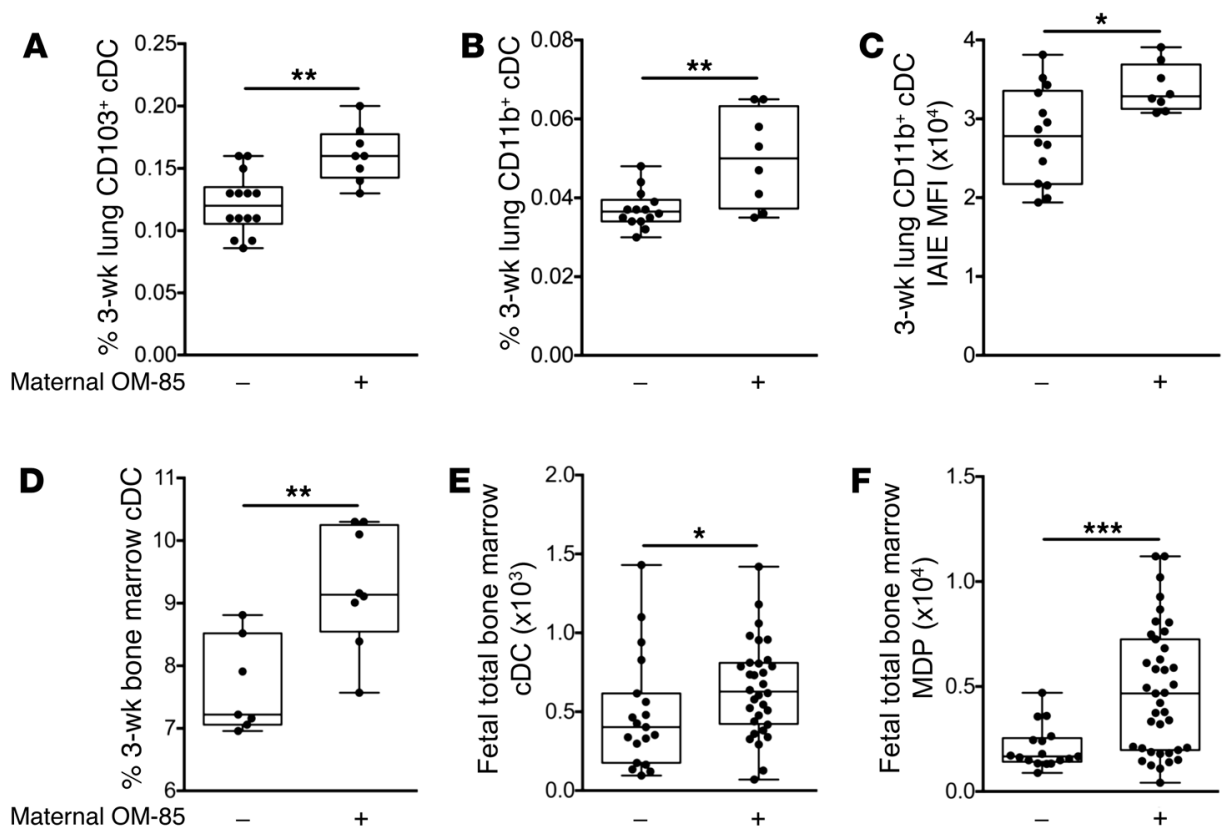

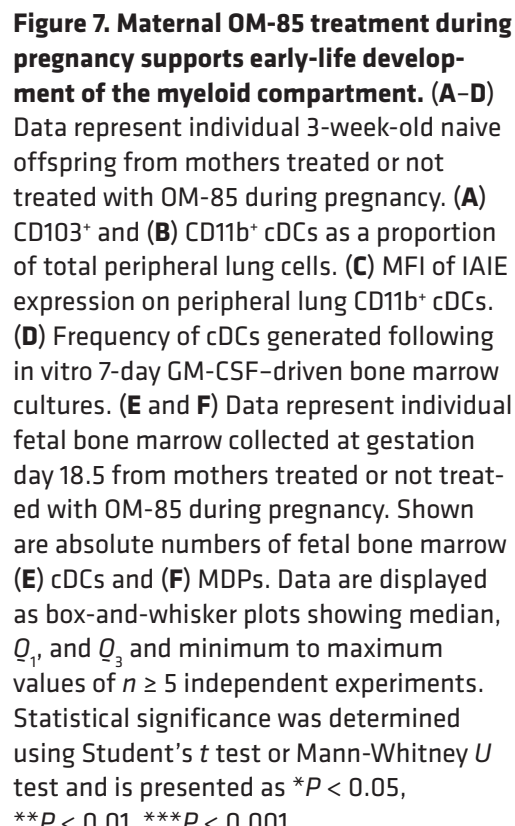

pregnancy supports early-life development of the myeloid compartment. (A-D)

Data represent individual 3-week-old naive erom mothers treated or not of total peripheral lung cells. (C) MFI of IAIE expression on peripheral lung CD11 ${ }^{+} \mathrm{CDCs}$. (D) Frequency of $\mathrm{CDCs}$ generated following day 18.5 from mothers treated or not treated with 0M-85 during pregnancy. Shown are absolute numbers of fetal bone marrow $O_{1}$, and $O_{3}$ and minimum to maximum values of $n \geq 5$ independent experiments. Statistical significance was determined test and is presented as ${ }^{*} P<0.05$ ${ }^{* *} P<0.01,{ }^{* *} P<0.001$.
\end{abstract}

\title{
Discussion
}

In this experimental model, allergen challenge via aerosol of animals sensitized in early life triggers accumulation of a Th2associated inflammatory cell infiltrate in respiratory tract tissues, and ensuing airway hyperresponsiveness, mimicking some of the hallmark features of atopic asthma. Consistent with earlier reports $(18,19)$, prominent within these infiltrates were activated $\mathrm{CD}^{+} \mathrm{T}^{\mathrm{m}}$ effs and Treg populations, with the accompanying buildup of an expanded population of $\mathrm{cDCs}$ and their transition (especially in the mucosa) from the passive/antigen surveillance phenotype $\left(\mathrm{IAIE}^{\mathrm{lo}}\right)$ to a functionally mature (IAIE ${ }^{\mathrm{hi}}$ ) state. We also demonstrate, for the first time to our knowledge, that these rapid changes in the population dynamics of cDCs in the challenged airways of sensitized animals are accompanied by concomitant depletion of committed cDCs from bone marrow, and parallel (presumably compensatory) expansion of upstream multipotent precursor compartments.

We further demonstrate that susceptibility to this aeroallergeninduced asthma-like response in the airways is markedly attenuated in young animals born to mothers given repeated doses of OM-85 during pregnancy. These findings mirror those previously reported by Conrad et al. (36) in a model of controlled maternal exposure to Acinetobacter lwoffii F78, which the authors attributed to changes in Th1/Th2 balance (49). In contrast, in the present study, accompanying this acquired resistant state following OM-85 treatment is increased capacity for expansion and functional activation of Tregs in the airway mucosa in response to aeroallergen challenge, with parallel attenuation of local cDC recruitment, activation, and trafficking to ADLNs. It is pertinent to note that this OM-85 treatment is not accompanied by overt attenuation of allergen-specific IgE production. This is similar to the situation described in humans undergoing successful allergen immunotherapy, who frequently display reduced inflammatory symptoms without major reduction in IgE production; this has been ascribed, inter alia, to boosting of Treg functions $(50,51)$.

Moreover, underpinning these OM-85 treatment effects in respiratory tract-associated tissues are a series of parallel changes in bone marrow DC progenitor populations at various stages of DC commitment, which are collectively consistent with the reduced draw on bone marrow $\mathrm{cDC}$ reserves in the treated group as a result of more effective control of the inflammatory milieu within the challenged mucosa. The key question is whether these changes in bone marrow of offspring from treated mothers are primary or secondary in this process.

In this regard, we (48) and Navarro et al. (47) have previously demonstrated that oral OM-85 treatment of rodents can directly promote generation in gut-associated tissues of mucosal-homing DCs that can bolster systemic natural Treg populations (including those in the airway mucosa) at baseline. Moreover, Navarro et al. (47) have demonstrated that these effects of OM-85 are Toll-like receptor-dependent (TLR-dependent), and similar findings have been reported in in vitro studies in a murine model (52). In the current model, airway mucosal Treg density and functional phenotype do not differ between OM-85-treated and nontreated groups at baseline, and the stimulatory effects of treatment are only evident following aeroallergen challenge (Figure 4, C-K). We posit therefore that $\mathrm{OM}-85$ treatment has affected the functionality of the airway mucosal cDCs that are responsible for programming Treg/Teff balance in the aerosol-induced $\mathrm{T}$ cell response, before their migration into the airway mucosa, i.e., at the bone marrow precursor stage. Several lines of indirect evidence support the possibility of OM-85 treatment effects in bone marrow: (a) Baseline IAIE expression on 6-week-old bone marrow cDCs is significantly reduced in offspring from treated mothers (Figure 6G), and corresponding GMP and MDP precursor compartments are expanded in the same animals (Figure 6, C and D). (b) At age 3 weeks when airway mucosal cDC networks are normally developmentally compromised with respect to baseline density, offspring from treated mothers display higher frequency of $\mathrm{CD}_{103}{ }^{+}$and $\mathrm{CD} 11 \mathrm{~b}^{+} \mathrm{cDC}$ in lung tissue digests (Figure 7, A and B) and higher $\mathrm{CDC}$ yields from bone marrow cultures 

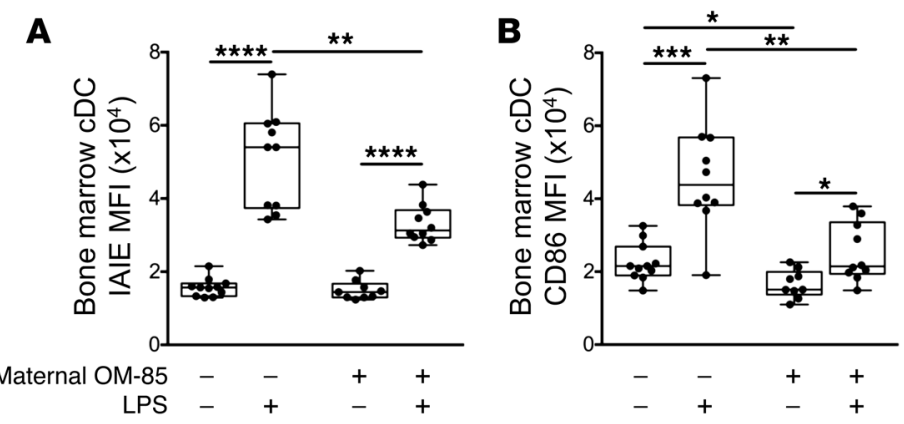

Figure 8. OM-85 treatment effects on bone marrow DCs in an independent inflammatory model. Shown is the MFI of (A) IAIE and (B) CD86 on bone marrow CDCs cultured for 7 days in the presence of GM-CSF with or without LPS for the last 24 hours. Data are presented comparing offspring from $0 \mathrm{M}-85$-treated and untreated mothers and displayed as box-and-whisker plots showing median, $Q_{1}$, and $Q_{3}$ and minimum to maximum values of $n=14$ independent experiments. Statistical significance was determined using Student's $t$ test or Mann-Whitney $U$ test for intergroup comparisons and paired Student's $t$ test or Wilcoxon signed-rank test for intragroup comparisons and is presented as ${ }^{*} P<0.05$, ${ }^{*} P<0.01,{ }^{* *} P<0.001,{ }^{* * *} P<0.0001$.

(Figure 7D). (c) The frequency of cDCs and their MDP precursors in fetal bone marrow are already increased in offspring from treated mothers by late gestation (Figure 7, E and F). Moreover, preliminary studies (Supplemental Figure 4) have demonstrated a direct stimulation effect of OM-85 feeding on the myeloid precursor compartment of adult nonpregnant mice, and our forerunner studies (16) have demonstrated a range of effects on myeloid and regulatory cell populations in maternal gestational tissues. However, the strongest evidence for treatment-related effects at the DC precursor stage comes from the studies on cDCs from 6-week-old GM-CSF-driven 7-day bone marrow cultures (Figure 8). The introduction of the archetypal proinflammatory stimulus bacterial LPS for the final 24 hours of these cultures triggers ultrahigh expression on cDCs from untreated controls of both IAIE and CD86, at levels likely to result in potentially pathological $\mathrm{T}$ cell hyperstimulation. However, this upregulation was more tightly controlled in cDCs from offspring of treated mothers, suggesting enhanced capacity to maintain homeostasis and avoid bystander damage to host tissues during immunoinflammatory responses to environmental stimuli.

We acknowledge several limitations to this study. Firstly, we have not addressed the question of whether OM-85 treatment influences susceptibility to primary allergic sensitization to inhalant allergens, and this merits future investigation, given that this process has also been shown to be controlled by ADLN-derived Tregs (53). Secondly, we have no information on the mechanism of transmission of orally delivered OM-85-associated signals to the bone marrow. Earlier studies from our group (48) and others (47) have demonstrated local activation of both $\mathrm{T}$ cells and myeloid cells in the gut wall and associated lymphoid tissues following OM-85 feeding, and it is possible that trafficking of representatives of either or both of these populations, or transmission of soluble signals generated at these sites, may be involved. Likewise, information on the gene target(s) in fetal bone marrow DC progenitors is not available, and will be the subject of future studies, along with possible effects on fetal thymus. We also have not formally demonstrated TLR-dependency of OM-85, although (as discussed above) this has been established in related models. Additionally, OM-85 dosing of mothers in this study spanned only the second half of gestation, and future studies need to investigate the impact of extending feeding to earlier stages. Moreover, additional dose-response studies are required to determine the minimal dosage of OM-85 required to mediate these effects. In this regard, recent studies (54) suggest that effective attenuation of allergic airway inflammation via direct OM-85 treatment may be attainable at a log-fold lower dose than that used in the current study.

Our goal in this study was to provide a scientific rationale for subsequent use of OM-85 during pregnancy in human mothers whose progeny are at risk of postnatal development of persistent atopy and/or asthma. The prime initial candidates for therapy in this regard are atopic asthmatic mothers $(55,56)$. The severity of asthma symptomatology in this group is exaggerated during pregnancy (57-59), likely as a consequence of the generalized Th2-skewing of immune functions associated with the pregnant state, and asthma exacerbations during pregnancy further increase asthma risk for their offspring (60). Moreover, susceptibility to respiratory infections exemplified by influenza virus and its associated symptom severity is likewise increased during pregnancy $(61,62)$ and (along with bacterial infections) is a risk factor for fetal growth restriction (63), which in turn is associated with increased risk for postnatal development of a range of noncommunicable diseases, including asthma $(64,65)$. In this regard, our forerunner studies on OM-85 use in pregnant mice have demonstrated strong protection against the effects of pathogen-associated challenge during pregnancy using high-dose LPS or live influenza, with respect to both preservation of pregnancy per se, and maintenance of normal maternal weight gain and associated fetal growth trajectories (16). In this system the principal treatment effect of OM-85 involved selective attenuation within gestational tissues of the intensity of the proinflammatory components (particularly TNF- $\alpha /$ IL-1/IL-6) of the myeloid innate immune response to pathogen, with parallel preservation of vigorous type 1 IFN-associated host defense networks (16). Moreover, we (48) and others (47) have also previously demonstrated marked attenuation of airway inflammation in OM-85-treated adult animals in models of experimental allergic airway inflammatory disease. On this basis, it can be argued that OM-85 use during pregnancy has potential direct shortterm benefits to mothers, as well as long-term benefits to their offspring in regard to reduced susceptibility to asthma development. The latter may also include enhanced resistance to early postnatal respiratory infections, given the OM-85-associated effects demonstrated above on increased airway mucosal $\mathrm{cDC}$ numbers and IAIE expression at baseline in 3-week-old weanlings, and studies are in progress to test this possibility.

A series of additional steps are required before progression to human trials with OM-85 in pregnancy. The first involves an independent assessment by regulators of relevant safety issues. In this regard there is a wide body of data available, including our own (16), on safe use during pregnancy in experimental animals. Direct human safety data for pregnancy are not presently available. However, there is a more than 30-year history of safe use in nonpregnant adult humans and children down to age 6 months, and this has proven sufficient for relevant US (66) (NIH) and Australian 
(67) (National Health and Medical Research Council) authorities to endorse and publicly fund multicenter clinical trials in infants, targeting protection against wheezing symptoms (including those associated with early infections) and subsequent asthma development. In this regard, it is evident that airway inflammation associated with infections and inhalant allergy act in synergy to drive asthma pathogenesis during childhood (35), and moreover that the earlier these episodic inflammatory events commence after birth, the greater is the risk for subsequent asthma (68-70). This provides a compelling argument for development of protective therapeutic strategies that can reduce susceptibility to either or both of these environmental stressors, from birth onward, and the possibility that this may be achievable prenatally with a readily available therapeutic such as OM-85 merits further detailed investigation.

\section{Methods}

\section{Animals}

Specific pathogen-free BALB/c mice and Sprague-Dawley rats were obtained from the Animal Resource Centre (Murdoch, Western Australia, Australia). All animals were housed under specific pathogenfree conditions at the Telethon Kids Institute Bioresources Facility, with a 12-hour light/12-hour dark cycle and access to an OVA-free diet and water ad libitum. In-house-bred BALB/c offspring of both sexes were used in these studies.

\section{Time-mated pregnancies}

Female BALB/c mice 8-12 weeks of age were time-mated with male studs between 8 and 26 weeks of age. Male studs were housed separately in individual cages. One to two females were housed in an individual male cage overnight, with the presence of a vaginal plug the following morning used as an indicator of mating. The day of vaginal plug detection was designated gestation day (GD) 0.5.

\section{OM-85}

OM-85 (OM Pharma) is an endotoxin-low lyophilized extract containing multiple TLR ligands derived from 8 major bacterial pathogens (Haemophilus influenzae, Streptococcus pneumoniae, Streptococcus pyogenes, Streptococcus viridans, Klebsiella pneumoniae, Klebsiella ozaenae, Staphylococcus aureus, and Neisseria catarrhalis) frequently associated with respiratory tract infections $(12,71)$.

\section{Maternal 0M-85 treatment protocol}

Based on previously optimized dosing concentrations $(16,48)$, timemated pregnant female $\mathrm{BALB} / \mathrm{c}$ mice selected at random received daily feeding of lyophilized OM-85 reconstituted in PBS to a concentration of $400 \mathrm{mg} / \mathrm{kg}$ body weight for the second half of gestation (GD9.5-17.5). Controls were left untreated. All treatments were performed from a single batch of OM-85 (batch 1812162).

\section{Offspring antigen sensitization and aerosol challenge}

Offspring from OM-85-treated or naive mothers were experimentally sensitized to OVA at the ages of 21 and 35 days via i.p. inoculation of $20 \mu$ g OVA (grade V; Sigma-Aldrich) emulsified in $1.3 \mathrm{mg}$ aluminium hydroxide (Alu-Gel-S, SERVA) in a total volume of $200 \mu$ l. On days 42,43 , and 44, sensitized offspring were exposed to OVA aerosol challenge (1\% wt/vol in PBS) for 30 minutes, delivered via ultrasonic nebulizer. Mice for airway hyperresponsiveness assessment received a single OVA aerosol challenge on day 42 for 30 minutes. All experimental mice were sacrificed 24 hours after final aerosol.

\section{Measurement of airway hyperresponsiveness}

Airway hyperresponsiveness to inhaled methacholine (MCh) was assessed 24 hours after a single OVA (1\% wt/vol in PBS) aerosol on day 42 following presensitization. The low-frequency forced oscillation technique (LFOT) was used to measure respiratory system input impedance $\left(\mathrm{Z}_{\mathrm{rs}}\right)$, as determined by previously optimized protocols (72). Briefly, BALB/c mice were anesthetized (40\% ketamine $100 \mathrm{mg} /$ $\mathrm{ml}, 10 \%$ xylazine $20 \mathrm{mg} / \mathrm{ml}, 50 \%$ saline; $1 \%$ body weight), tracheotomized, and ventilated (Legacy flexiVent, SCIREQ) at 450 breaths/min with a tidal volume of $8 \mathrm{ml} / \mathrm{kg}$ and $2 \mathrm{cmH}_{2} \mathrm{O}$ positive end-expiratory pressure. Lung volume history was standardized for each individual mouse before measurement of experimental lung mechanics. $\mathrm{Z}_{\mathrm{rs}}$ was measured during 16 -second periods of apnea using a signal containing 19 mutually prime sinusoidal frequencies ranging from 0.25 to 19.625 $\mathrm{Hz}$. The constant-phase model was fit to $\mathrm{Z}_{\mathrm{rs}}$ in order to calculate changes in airway resistance $\left(\mathrm{R}_{\text {aw }}\right)$. Ventilated $B A L B / c$ mice had 5 baseline measurements recorded, with 10-second aerosol challenge of saline followed by semi-log-fold increasing dose concentrations of $\mathrm{MCh}$ ranging from 0.1 to $30 \mathrm{mg} / \mathrm{ml}$ to assess for airway hyperresponsiveness. Five LFOT measurements were recorded after each MCh dose at 1-minute intervals. Dose-response curves were generated using the maximum response recorded for $\mathrm{R}_{\mathrm{aw}}$.

\section{Tissue collection}

Fetal. Pregnant BALB/c mice were sacrificed on GD18.5. Both horns of the uterus were removed, and fetuses were sacrificed via decapitation. Hind legs were removed, cleaned of remaining tissue, and stored in cold PBS plus 0.1\% BSA. Dead fetuses were excluded.

Three-week-old offspring. Offspring were sacrificed at 21 days of age. Lungs were perfused via cardiac flush with $2 \mathrm{ml}$ cold PBS plus $0.1 \%$ BSA. Peripheral lung and the femur and tibia from both hind legs were collected.

Six-week-old offspring. Offspring were sacrificed at 45 days of age. Lungs were perfused via cardiac flush with $2 \mathrm{ml}$ cold PBS plus $0.1 \%$ BSA. Parathymic and mediastinal (airway draining) lymph nodes (ADLNs), trachea, peripheral lung, and the femur and tibia from both hind legs were collected. Blood was collected via cardiac puncture at time of autopsy.

\section{Passive cutaneous anaphylaxis IgE assay}

In vivo passive cutaneous anaphylaxis assays were performed using male Sprague-Dawley rats 10 weeks of age. Individual BALB/c serum samples were prepared as serial 1:2 dilutions with a final sample volume of $55 \mu \mathrm{l}$. Sprague-Dawley rats were anesthetized via i.p. injection of $4 \mathrm{ml} \mathrm{5.71 \%} \mathrm{chloral} \mathrm{hydrate} \mathrm{(Sigma-Aldrich)} \mathrm{in} \mathrm{PBS.} \mathrm{Once} \mathrm{anesthe-}$ tized, rats had their back closely shaved to remove all hair, and $50 \mu \mathrm{l}$ of each sample was injected s.c. down the back. Twenty-four hours later, rats were anesthetized with chloral hydrate and injected i.v. with $2 \mathrm{ml}$ of a 1:1 antigen/dye solution containing $4 \mathrm{mg} / \mathrm{ml}$ OVA in PBS and 1\% Evans blue dye (Sigma-Aldrich). Blue s.c. injection sites after 15-30 minutes indicate serum samples positive for OVA-specific IgE. The highest positive serum dilution for each sample was recorded, and animals were euthanized with $600 \mu$ l Lethabarb (Virbac) intravenously. 


\section{Single-cell suspension preparation}

Airway tissue and fetal bone marrow. ADLN, trachea, peripheral lung, and fetal bone marrow single-cell suspensions were prepared by mincing of excised tissue/bone into smaller pieces and resuspension in $10 \mathrm{ml} \mathrm{GKN} \mathrm{(11} \mathrm{mM} \mathrm{D-glucose,} 5.5 \mathrm{mM} \mathrm{KCl}, 137 \mathrm{mM} \mathrm{NaCl}, 25 \mathrm{mM}$ $\mathrm{Na}_{2} \mathrm{HPO}_{4}$ ) plus $10 \%$ FCS (Serana) with collagenase IV (Worthington Biochemical Corp.) and DNase (Sigma-Aldrich) for enzymatic digestion at $37^{\circ} \mathrm{C}$ under gentle agitation for 30 minutes (ADLN and trachea), 60 minutes (fetal bone marrow), or 90 minutes (peripheral lung). Following digestion, tissues were disaggregated via manual pipetting and filtered through sterile cotton wool columns. Cell suspensions were centrifuged and pellets resuspended in red blood cell ( $\mathrm{rbc} ; 17 \mathrm{mM}$ Tris$\mathrm{HCl}, 0.14 \mathrm{M} \mathrm{NH}_{4} \mathrm{Cl}$ at $\mathrm{pH}$ 7.2) lysis buffer for 3 minutes. Cells were washed with cold PBS and pelleted. Supernatant was removed and pellets resuspended in PBS plus $0.1 \%$ BSA for total cell counts.

Three- and six-week-old bone marrow. Long bones were flushed with $10 \mathrm{ml} \mathrm{GKN}$ plus $5 \%$ FCS using a 25-gauge needle. Cells were disaggregated by manual pipetting and filtered through a sterile cotton wool column. Filtered cells were washed with GKN plus 5\% FCS and centrifuged at 754 $g$ for 8 minutes at $4^{\circ} \mathrm{C}$. Supernatant was removed and pellets resuspended in rbc lysis buffer for 5 minutes. Cells were washed in cold PBS and centrifuged and pellets resuspended in PBS plus $0.1 \%$ BSA for total cell counts.

\section{Bronchoalveolar lavage and differential cell counts}

Bronchoalveolar lavage (BAL) fluid was collected via tracheal cannula flushing the lungs 3 times with $800 \mu \mathrm{l}$ cold PBS plus $0.1 \%$ BSA. BAL cells were resuspended in $300 \mu \mathrm{l} \mathrm{rbc}$ lysis buffer for 4 minutes. Cells were washed with cold PBS and spun, and pellets resuspended in $100 \mu \mathrm{l}$ cold PBS plus 0.1\% BSA for counting. BAL samples were counted with trypan blue (LabChem, Thermo Fisher Scientific) using a hemocytometer and counting to a minimum of 100 leukocytes. $1 \times 10^{5}$ cells for each individual sample were spun onto Superfrost Plus microscope slides (LabServ, Thermo Fisher Scientific). Cytospin cell preparations were stained using Diff-Quik (Rapid Stain Kit, Perth Scientific) and differential cell counts performed by counting of at least 300 cells per cytospin.

\section{Bone marrow cultures}

Three-week offspring. Single-cell bone marrow suspensions (previously described) were washed with $20 \mathrm{ml}$ cold PBS plus $0.1 \%$ BSA and centrifuged at $1,800 \mathrm{rpm}$ for 8 minutes at $4^{\circ} \mathrm{C}$. Cells were resuspended in RPMI-10 Complete Medium (RPMI 1640, 10\% FCS, 2 mM L-glutamine, $50 \mu \mathrm{M} 2-\beta$-mercaptoethanol [Sigma-Aldrich], $5 \mu \mathrm{g} / \mathrm{ml}$ gentamycin [Pfizer], and $10 \mathrm{ng} / \mathrm{ml} \mathrm{GM-CSF}$ ) at a concentration of $8 \times 10^{5}$ cells per ml. One-milliliter aliquots were seeded onto 24 -well treated cell culture plates and incubated at $37^{\circ} \mathrm{C}$ and $5 \% \mathrm{CO}_{2}$ in a water-jacketed incubator. At 48 hours, culture medium was aspirated, and wells were washed with $1 \mathrm{ml}$ RPMI supplemented with $2 \mathrm{mM}$ L-glutamine, $50 \mu \mathrm{M}$ $2-\beta$-mercaptoethanol, and $5 \mu \mathrm{g} / \mathrm{ml}$ gentamycin. Wash was aspirated, and $1 \mathrm{ml}$ of fresh RPMI-10 Complete Medium was added to wells. After 6 days, cells were harvested and wells washed twice with $500 \mu \mathrm{l}$ RPMI10. Cells were centrifuged and pellets resuspended in $500 \mu \mathrm{RPMI}-10$ to perform total cell counts. Following counts, cells were resuspended at a density of $1 \times 10^{6}$ cells $/ \mathrm{ml}$ in RPMI-10 Complete Medium, and 1-ml aliquots were reseeded on a 24 -well treated cell culture plate. After 24 hours, cells were harvested for flow cytometric phenotypic analysis.

Six-week offspring. Culture days 1-5 were as described for 3-week offspring. On day 6 , cells were harvested into $15-\mathrm{ml}$ conical tubes and wells washed twice with $500 \mu \mathrm{l}$ RPMI-10. Cells were centrifuged and pellets resuspended in $500 \mu \mathrm{l}$ RPMI-10 to perform total cell counts. Following counts, cells were resuspended at a density of $1 \times 10^{6}$ cells/ $\mathrm{ml}$ in RPMI-10 Complete Medium. One-milliliter aliquots were reseeded on a 24-well treated cell culture plate, and $1 \mathrm{ng} / \mathrm{ml} \mathrm{LPS} \mathrm{was} \mathrm{added} \mathrm{to}$ each well. Cells were cultured in the presence of LPS for 24 hours. After 24 hours, cells were harvested for flow cytometric phenotypic analysis.

\section{Flow cytometry}

Single-cell suspensions (as described above) were used for all immunostaining. Panels of mAbs were developed to enable phenotypic characterization of airway $\mathrm{T}$ cell, myeloid cell, bone marrow hematopoietic stem and progenitor cell, and bone marrow committed myeloid cell populations, as summarized in Supplemental Tables 1-4. Intracellular staining for FoxP3, CTLA-4, and Ki67 was performed using a FoxP3 intracellular staining buffer set (eBioscience). Acquisition was performed on a 4-laser LSR Fortessa (BD Biosciences). All samples were kept as individuals and not pooled. Immune cell phenotyping was analyzed using FlowJo software (version 10.1, Tree Star), and associated gating strategies are outlined in Supplemental Figures 5-7. Fluorescent minus one (FMO) staining controls were used for all panels.

\section{viSNE analysis}

ADLN, trachea, and peripheral lung FCS files, with software compensation applied, were uploaded to the Cytobank platform and analyzed using established methods $(73,74)$. The software transformed the data to ArcSinh scales. Antibodies as summarized in Supplemental Table 1 were used for $\mathrm{T}$ cell subset identification to create viSNE maps (Cytobank) using a total of 10,000 (ADLN and peripheral lung) or 3,000 (trachea) cells per sample.

\section{Statistics}

Statistical analysis and graphing was performed using GraphPad Prism (version 7.0a, GraphPad Software). Statistical significance of $P$ less than 0.05 was considered significant. Unpaired, 2-tailed Student's $t$ test or Mann-Whitney $U$ test was used based on distribution of the data as determined by D'Agostino-Pearson omnibus normality test, unless otherwise stated. The data were not corrected for multiple testing, because the analyses were not ad hoc but at each stage address a series of specific hypotheses, each of which is based on a priori knowledge of underlying mechanisms.

\section{Study approval}

All animal experiments were formally approved by the Telethon Kids Institute Animal Ethics Committee, which operates under guidelines developed by the National Health and Medical Research Council of Australia for the care and use of animals in scientific research.

\section{Author contributions}

KTM, PGH, and DHS designed the study. PGH and DHS supervised the study. KTM, NMS, JFLJ, JL, and ANL performed the experiments. KTM, NMS, JFLJ, JL, ANL, and DHS analyzed the data. PAS contributed to the project design, methodology, and discussions on data interpretation. SAR contributed to the project design and methodology. CP contributed to initial project design. KTM, PGH, and DHS wrote the manuscript. All authors reviewed the final manuscript. 


\section{Acknowledgments}

The authors acknowledge the animal technicians at the Telethon Kids Institute Bioresources Facility. This study was funded by the National Health and Medical Research Council of Australia (APP 1047212).
Address correspondence to: Deborah H. Strickland, Northern Entrance, Perth Children's Hospital, 15 Hospital Avenue, Nedlands, Western Australia 6009, Australia. Phone: 61.8.6319.1528; Email: Deb.Strickland@telethonkids.org.au.
1. von Mutius E, Radon K. Living on a farm: impact on asthma induction and clinical course. Immunol Allergy Clin North Am. 2008;28(3):631-647.

2. Ege MJ, et al. Exposure to environmental microorganisms and childhood asthma. N Engl JMed. 2011;364(8):701-709.

3. Stein MM, et al. Innate immunity and asthma risk in Amish and Hutterite farm children. $N$ Engl J Med. 2016;375(5):411-421.

4. Schaub B, et al. Maternal farm exposure modulates neonatal immune mechanisms through regulatory T cells. J Allergy Clin Immunol. 2009;123(4):774-782.e5.

5. Schuijs MJ, et al. Farm dust and endotoxin protect against allergy through A20 induction in lung epithelial cells. Science. 2015;349(6252):1106-1110.

6. Holt PG, Sly PD. Environmental microbial exposure and protection against asthma. N Engl JMed. 2015;373(26):2576-2578.

7. Ege MJ, et al. Prenatal farm exposure is related to the expression of receptors of the innate immunity and to atopic sensitization in school-age children. JAllergy Clin Immunol. 2006;117(4):817-823.

8. Lisciandro JG, et al. Neonatal antigen-presenting cells are functionally more quiescent in children born under traditional compared with modern environmental conditions. J Allergy Clin Immunol. 2012;130(5):1167-1174.e10.

9. Adegnika AA, et al. Pregnancy-associated malaria affects toll-like receptor ligand-induced cytokine responses in cord blood. J Infect Dis. 2008;198(6):928-936.

10. Bisseye C, van der Sande M, Morgan WD, Holder AA, Pinder M, Ismaili J. Plasmodium falciparum infection of the placenta impacts on the Thelper type 1 (Th1)/Th2 balance of neonatal T cells through CD4(+)CD25(+) forkhead box P3(+) regulatory $\mathrm{T}$ cells and interleukin-10. Clin Exp Immunol. 2009;158(3):287-293.

11. Schaad UB, Mütterlein R, Goffin H, BV-Child Study Group. Immunostimulation with OM-85 in children with recurrent infections of the upper respiratory tract: a double-blind, placebocontrolled multicenter study. Chest. 2002;122(6):2042-2049.

12. Razi CH, et al. The immunostimulant OM-85 BV prevents wheezing attacks in preschool children. J Allergy Clin Immunol. 2010;126(4):763-769.

13. Collet JP, Shapiro P, Ernst P, Renzi T, Ducruet T, Robinson A. Effects of an immunostimulating agent on acute exacerbations and hospitalizations in patients with chronic obstructive pulmonary disease. The PARI-IS Study Steering Committee and Research Group. Prevention of Acute Respiratory Infection by an Immunostimulant. Am J Respir Crit Care Med.1997;156(6):1719-1724.

14. Orcel B, Delclaux B, Baud M, Derenne JP. Oral immunization with bacterial extracts for protection against acute bronchitis in elderly institutionalized patients with chronic bronchitis. Eur Respir J. 1994;7(3):446-452.
15. Solèr M, Mütterlein R, Cozma G, Swiss-German OM-85 Study Group. Double-blind study of OM-85 in patients with chronic bronchitis or mild chronic obstructive pulmonary disease. Respiration. 2007;74(1):26-32.

16. Scott NM, et al. Protection against maternal infection-associated fetal growth restriction: proof-of-concept with a microbial-derived immunomodulator. Mucosal Immunol. 2017;10(3):789-801.

17. Holt PG, Upham JW, Sly PD. Contemporaneous maturation of immunologic and respiratory functions during early childhood: implications for development of asthma prevention strategies. J Allergy Clin Immunol. 2005;116(1):16-24.

18. Huh JC, et al. Bidirectional interactions between antigen-bearing respiratory tract dendritic cells (DCs) and T cells precede the late phase reaction in experimental asthma: DC activation occurs in the airway mucosa but not in the lung parenchyma. JExp Med. 2003;198(1):19-30.

19. Stumbles PA, et al. Resting respiratory tract dendritic cells preferentially stimulate $\mathrm{T}$ helper cell type 2 (Th2) responses and require obligatory cytokine signals for induction of Th1 immunity. J Exp Med.1998;188(11):2019-2031.

20. Vermaelen KY, Carro-Muino I, Lambrecht BN, Pauwels RA. Specific migratory dendritic cells rapidly transport antigen from the airways to the thoracic lymph nodes. J Exp Med. 2001;193(1):51-60.

21. Akdis $\mathrm{M}$, et al. Immune responses in healthy and allergic individuals are characterized by a fine balance between allergen-specific $\mathrm{T}$ regulatory 1 and T helper 2 cells. J Exp Med. 2004;199(11):1567-1575.

22. Strickland DH, et al. Reversal of airway hyperresponsiveness by induction of airway mucosal $\mathrm{CD}^{+} \mathrm{CD} 25^{+}$regulatory T cells. J Exp Med. 2006;203(12):2649-2660.

23. Cederbom L, Hall H, Ivars F. CD $4{ }^{+} \mathrm{CD} 25^{+}$regulatory $\mathrm{T}$ cells down-regulate co-stimulatory molecules on antigen-presenting cells. Eur J Immunol. 2000;30(6):1538-1543.

24. Lewkowich IP, et al. CD $4^{+} \mathrm{CD} 25^{+} \mathrm{T}$ cells protect against experimentally induced asthma and alter pulmonary dendritic cell phenotype and function. J Exp Med. 2005;202(11):1549-1561.

25. de Heer HJ, et al. Essential role of lung plasmacytoid dendritic cells in preventing asthmatic reactions to harmless inhaled antigen. JExp Med. 2004;200(1):89-98.

26. Gill MA, et al. Mobilization of plasmacytoid and myeloid dendritic cells to mucosal sites in children with respiratory syncytial virus and other viral respiratory infections. J Infect Dis. 2005;191(7):1105-1115.

27. Holt PG, Haining S, Nelson DJ, Sedgwick JD. Origin and steady-state turnover of class II MHC-bearing dendritic cells in the epithelium of the conducting airways. JImmunol. 1994;153(1):256-261.

28. McWilliam AS, Nelson D, Thomas JA, Holt PG.
Rapid dendritic cell recruitment is a hallmark of the acute inflammatory response at mucosal surfaces. JExp Med. 1994;179(4):1331-1336.

29. McWilliam AS, et al. Dendritic cells are recruited into the airway epithelium during the inflammatory response to a broad spectrum of stimuli. JExp Med. 1996;184(6):2429-2432.

30. Jahnsen FL, et al. Accelerated antigen sampling and transport by airway mucosal dendritic cells following inhalation of a bacterial stimulus. J Immunol. 2006;177(9):5861-5867.

31. Tschernig T, Debertin AS, Paulsen F, Kleemann WJ, Pabst R. Dendritic cells in the mucosa of the human trachea are not regularly found in the first year of life. Thorax. 2001;56(6):427-431.

32. Heier I, Malmström K, Sajantila A, Lohi J, Mäkelä M, Jahnsen FL. Characterisation of bronchusassociated lymphoid tissue and antigen-presenting cells in central airway mucosa of children. Thorax. 2011;66(2):151-156.

33. Nelson DJ, McMenamin C, McWilliam AS, Brenan M, Holt PG. Development of the airway intraepithelial dendritic cell network in the rat from class II major histocompatibility (Ia)-negative precursors: differential regulation of Ia expression at different levels of the respiratory tract. J Exp Med. 1994;179(1):203-212.

34. Nelson DJ, Holt PG. Defective regional immunity in the respiratory tract of neonates is attributable to hyporesponsiveness of local dendritic cells to activation signals. JImmunol. 1995;155(7):3517-3524.

35. Holt PG, Sly PD. Viral infections and atopy in asthma pathogenesis: new rationales for asthma prevention and treatment. Nat Med. 2012;18(5):726-735.

36. Conrad ML, et al. Maternal TLR signaling is required for prenatal asthma protection by the nonpathogenic microbe Acinetobacter lwoffii F78. JExp Med. 2009;206(13):2869-2877.

37. Strickland DH, et al. Defective aeroallergen surveillance by airway mucosal dendritic cells as a determinant of risk for persistent airways hyper-responsiveness in experimental asthma. Mucosal Immunol. 2012;5(3):332-341.

38. Plantinga $\mathrm{M}$, et al. Conventional and monocyte-derived $\mathrm{CD} 11 \mathrm{~b}(+)$ dendritic cells initiate and maintain T helper 2 cell-mediated immunity to house dust mite allergen. Immunity. 2013;38(2):322-335.

39. Kool M, et al. Alum adjuvant boosts adaptive immunity by inducing uric acid and activating inflammatory dendritic cells. J Exp Med. 2008;205(4):869-882.

40. Hammad H, et al. Inflammatory dendritic cells not basophils - are necessary and sufficient for induction of Th2 immunity to inhaled house dust mite allergen. JExp Med. 2010;207(10):2097-2111.

41. Denburg JA, Sehmi R, Saito H, Pil-Seob J, Inman MD, O'Byrne PM. Systemic aspects of allergic disease: bone marrow responses. J Allergy Clin Immunol. 2000;106(5 suppl):S242-S246. 
42. Akashi K, Traver D, Miyamoto T, Weissman IL. A clonogenic common myeloid progenitor that gives rise to all myeloid lineages. Nature. 2000;404(6774):193-197.

43. Iwasaki $\mathrm{H}$, et al. Identification of eosinophil lineage-committed progenitors in the murine bone marrow. JExp Med. 2005;201(12):1891-1897.

44. Fogg DK, et al. A clonogenic bone marrow progenitor specific for macrophages and dendritic cells. Science. 2006;311(5757):83-87.

45. Auffray C, et al. CX(3)CR1(+) CD115(+) CD135(+) common macrophage/DC precursors and the role of CX(3)CR1 in their response to inflammation. J Exp Med. 2009;206(3):595-606.

46. del Rio ML, et al. CX3CR1 ${ }^{+}$c-kit ${ }^{+}$bone marrow cells give rise to $\mathrm{CD}_{103}{ }^{+}$and $\mathrm{CD} 103^{-}$dendritic cells with distinct functional properties. J Immunol. 2008;181(9):6178-6188.

47. Navarro S, et al. The oral administration of bacterial extracts prevents asthma via the recruitment of regulatory T cells to the airways. Mucosal Immunol. 2011;4(1):53-65.

48. Strickland DH, Judd S, Thomas JA, Larcombe AN, Sly PD, Holt PG. Boosting airway T-regulatory cells by gastrointestinal stimulation as a strategy for asthma control. Mucosal Immunol. 2011;4(1):43-52.

49. Brand S, et al. Epigenetic regulation in murine offspring as a novel mechanism for transmaternal asthma protection induced by microbes. J Allergy Clin Immunol. 2011;128(3):618-625.e1.

50. Larché M, Akdis CA, Valenta R. Immunological mechanisms of allergen-specific immunotherapy. Nat Rev Immunol. 2006;6(10):761-771.

51. Akdis M, Akdis CA. Mechanisms of allergen-specific immunotherapy: multiple suppressor factors at work in immune tolerance to allergens. J Allergy Clin Immunol. 2014;133(3):621-631.

52. Dang AT, Pasquali C, Ludigs K, Guarda G. OM-85 is an immunomodulator of interferon- $\beta$ production and inflammasome activity. Sci Rep. 2017;7:43844.

53. Holt PG, Strickland DH, Wikström ME, Jahnsen
FL. Regulation of immunological homeostasis in the respiratory tract. Nat Rev Immunol. 2008;8(2):142-152.

54. Holt PG, Strickland DH. Low dose treatment of mice with bacterial extract (OM-85) for attenuation of experimental atopic asthma in mice. Allergol Immunopathol (Madr). 2017;45(3):310-311.

55. Tariq SM, Matthews SM, Hakim EA, Stevens M, Arshad SH, Hide DW. The prevalence of and risk factors for atopy in early childhood: a whole population birth cohort study. J Allergy Clin Immunol. 1998;101(5):587-593.

56. Litonjua AA, Carey VJ, Burge HA, Weiss ST, Gold DR. Parental history and the risk for childhood asthma. Does mother confer more risk than father? Am J Respir Crit Care Med. 1998;158(1):176-181.

57. Schatz M, et al. The course of asthma during pregnancy, post partum, and with successive pregnancies: a prospective analysis. J Allergy Clin Immunol. 1988;81(3):509-517.

58. Schatz M, et al. Asthma morbidity during pregnancy can be predicted by severity classification. J Allergy Clin Immunol. 2003;112(2):283-288.

59. Murphy VE, Gibson P, Talbot PI, Clifton VL. Severe asthma exacerbations during pregnancy. Obstet Gynecol. 2005;106(5 pt 1):1046-1054.

60. Martel MJ, et al. Control and severity of asthma during pregnancy are associated with asthma incidence in offspring: two-stage case-control study. Eur Respir J. 2009;34(3):579-587.

61. Dodds L, et al. Impact of influenza exposure on rates of hospital admissions and physician visits because of respiratory illness among pregnant women. CMAJ. 2007;176(4):463-468.

62. Jamieson DJ, et al. H1N1 2009 influenza virus infection during pregnancy in the USA. Lancet. 2009;374(9688):451-458.

63. McNeil SA, et al. Effect of respiratory hospitalization during pregnancy on infant outcomes. Am J Obstet Gynecol. 2011;204(6 suppl 1):S54-S57.

64. Barker DJ. Adult consequences of fetal growth restriction. Clin Obstet Gynecol.
2006;49(2):270-283.

65. Xu XF, Li YJ, Sheng YJ, Liu JL, Tang LF, Chen ZM. Effect of low birth weight on childhood asthma: a meta-analysis. BMC Pediatr. 2014;14:275.

66. University of Arizona. Oral Bacterial Extract for the Prevention of Wheezing Lower Respiratory Tract Illness (ORBEX). NIH Website. https:// clinicaltrials.gov/ct2/show/NCT02148796. Accessed August 31, 2018.

67. The University of Queensland. OM-85 in the prevention of asthma in high-risk children. Australia New Zealand Clinical Trials Registry Website. https://www.anzctr.org.au/Trial/Registration/ TrialReview.aspx?id=362459\&showHistory= true\&isReview=true. Updated June 15, 2016. Accessed August 31, 2018.

68. Bisgaard H, et al. Childhood asthma after bacterial colonization of the airway in neonates. $N$ Engl J Med. 2007;357(15):1487-1495.

69. Teo SM, et al. The infant nasopharyngeal microbiome impacts severity of lower respiratory infection and risk of asthma development. Cell Host Microbe. 2015;17(5):704-715.

70. Kusel MM, et al. Early-life respiratory viral infections, atopic sensitization, and risk of subsequent development of persistent asthma. J Allergy Clin Immunol. 2007;119(5):1105-1110.

71. Rozy A, Chorostowska-Wynimko J. Bacterial immunostimulants - mechanism of action and clinical application in respiratory diseases. Pneumonol Alergol Pol. 2008;76(5):353-359.

72. Zosky GR, et al. Ovalbumin-sensitized mice are good models for airway hyperresponsiveness but not acute physiological responses to allergen inhalation. Clin Exp Allergy. 2008;38(5):829-838.

73. Kotecha N, Krutzik PO, Irish JM. Web-based analysis and publication of flow cytometry experiments. Curr Protoc Cytom. 2010; Chapter 10:Unit 10.17.

74. Diggins KE, Ferrell PB Jr, Irish JM. Methods for discovery and characterization of cell subsets in high dimensional mass cytometry data. Methods. 2015;82:55-63 